\title{
Clinical Pharmacokinetics of Systemically Administered Antileishmanial Drugs
}

\author{
Anke E. Kip ${ }^{1,2} \cdot$ Jan H. M. Schellens ${ }^{2,3} \cdot$ Jos H. Beijnen ${ }^{1,2,3}$ - Thomas P. C. Dorlo ${ }^{1,4}$
}

Published online: 29 July 2017

(c) The Author(s) 2017. This article is an open access publication

\begin{abstract}
This review describes the pharmacokinetic properties of the systemically administered antileishmanial drugs pentavalent antimony, paromomycin, pentamidine, miltefosine and amphotericin B (AMB), including their absorption, distribution, metabolism and excretion and potential drug-drug interactions. This overview provides an understanding of their clinical pharmacokinetics, which could assist in rationalising and optimising treatment regimens, especially in combining multiple antileishmanial drugs in an attempt to increase efficacy and shorten treatment duration. Pentavalent antimony pharmacokinetics are characterised by rapid renal excretion of unchanged drug and a long terminal
\end{abstract}

Electronic supplementary material The online version of this article (doi:10.1007/s40262-017-0570-0) contains supplementary material, which is available to authorized users.

Thomas P. C. Dorlo

t.dorlo@nki.nl

1 Department of Pharmacy and Pharmacology, Antoni van Leeuwenhoek Hospital/MC Slotervaart, Amsterdam, The Netherlands

2 Division of Pharmacoepidemiology and Clinical Pharmacology, Faculty of Science, Utrecht Institute for Pharmaceutical Sciences (UIPS), Utrecht University, Utrecht, The Netherlands

3 Department of Clinical Pharmacology, Antoni van Leeuwenhoek Hospital/The Netherlands Cancer Institute, Amsterdam, The Netherlands

4 Pharmacometrics Research Group, Department of Pharmaceutical Biosciences, Uppsala University, Uppsala, Sweden half-life, potentially due to intracellular conversion to trivalent antimony. Pentamidine is the only antileishmanial drug metabolised by cytochrome P450 enzymes. Paromomycin is excreted by the kidneys unchanged and is eliminated fastest of all antileishmanial drugs. Miltefosine pharmacokinetics are characterized by a long terminal half-life and extensive accumulation during treatment. AMB pharmacokinetics differ per drug formulation, with a fast renal and faecal excretion of AMB deoxylate but a much slower clearance of liposomal $\mathrm{AMB}$ resulting in an approximately ten-fold higher exposure. AMB and pentamidine pharmacokinetics have never been evaluated in leishmaniasis patients. Studies linking exposure to effect would be required to define target exposure levels in dose optimisation but have only been performed for miltefosine. Limited research has been conducted on exposure at the drug's site of action, such as skin exposure in cutaneous leishmaniasis patients after systemic administration. Pharmacokinetic data on special patient populations such as HIV co-infected patients are mostly lacking. More research in these areas will help improve clinical outcomes by informed dosing and combination of drugs. 


\section{Key Points}

Due to very limited treatment options for leishmaniasis patients, optimisation of current drug dosages and drug combinations is of utmost importance, for which this review provides a solid pharmacokinetic basis.

This review describes the absorption, distribution, metabolism and excretion, as well as the clinical pharmacokinetics and potential drug-drug interactions of the antileishmanial drugs pentavalent antimonials, paromomycin, pentamidine, miltefosine and amphotericin B in the context of leishmaniasis.

The pharmacokinetics of two out of five antileishmanial drugs have never been evaluated in leishmaniasis patients. Exposure-response studies and pharmacokinetic data in special patient populations such as HIV co-infected patients are lacking. More research in this area will improve clinical outcomes via informed dosing regimens and combinations of drugs.

\section{Introduction}

Leishmaniasis is a neglected tropical disease caused by the Leishmania parasite and can cause diverse clinical manifestations depending on the subspecies responsible for the infection and the host immune response. The two main types are the systemic disease visceral leishmaniasis (VL) and the skin infection cutaneous leishmaniasis (CL). Several drugs (Table 1) are currently used in clinical practice in treatment of both VL and CL [1,2] but clinical guidelines differ by region. Clinical results obtained in one area of endemicity cannot be extrapolated to other geographical areas as efficacies have been shown to vary widely between countries and parasite subspecies (reviewed in Croft and Olliaro [3] and Sundar and Singh [4]).

Rising levels of resistance against antimonials, mostly in India, and potentially miltefosine, is a great pitfall in the treatment of leishmaniasis patients $[4,5]$. Available treatment options are limited, especially in vulnerable patient populations such as paediatric leishmaniasis patients and HIV patients co-infected with VL. Therefore, several new combinations of drugs are currently being tested to improve the efficacy of antileishmanial therapies. Furthermore, combination therapies could possibly shorten treatment duration.

Table 1 Overview of antileishmanial drugs systemically administered in treatment of visceral and/or cutaneous leishmaniasis (only includes information in human subjects, unless indicated otherwise)

\begin{tabular}{|c|c|c|c|c|c|c|}
\hline \multirow{2}{*}{$\begin{array}{l}\text { Antileishmanial } \\
\text { drug }\end{array}$} & \multirow[t]{2}{*}{ Formulations } & \multirow{2}{*}{$\begin{array}{l}\text { Route of } \\
\text { administration }\end{array}$} & \multicolumn{2}{|l|}{ Distribution } & \multirow[t]{2}{*}{ Metabolism } & \multirow[t]{2}{*}{ Excretion } \\
\hline & & & $\begin{array}{l}\text { Highest } \\
\text { accumulation }\end{array}$ & Skin & & \\
\hline $\begin{array}{l}\text { Pentavalent } \\
\text { antimonials }\end{array}$ & $\begin{array}{l}\text { Sodium } \\
\text { stibugluconate } \\
\text { (SSG) } \\
\text { Meglumine } \\
\text { Antimoniate } \\
\text { (MA) }\end{array}$ & IM/IV & Liver, thyroid, heart & Confirmed & $\begin{array}{l}\text { Intracellular } \\
\quad \text { reduction to } \mathrm{Sb}^{\mathrm{III}}\end{array}$ & Renal clearance \\
\hline Paromomycin & $\begin{array}{l}\text { Paromomycin } \\
\text { sulphate }\end{array}$ & $\mathrm{IM}$ & Not reported & Not reported & Not metabolized & Renal clearance \\
\hline Pentamidine & $\begin{array}{r}\text { Pentamidine } \\
\text { dimesylate } \\
\text { Pentamidine } \\
\text { isethionate }\end{array}$ & IM/IV & $\begin{array}{l}\text { Kidney, liver, spleen, } \\
\text { adrenal glands }\end{array}$ & Not reported & $\begin{array}{l}\text { CYP1A1 } \\
\text { (CYP2D6, } \\
\text { CYP3A5 and } \\
\text { CYP4A11) }\end{array}$ & Not excreted unchanged \\
\hline Miltefosine & Miltefosine & Oral & $\begin{array}{l}\text { Not reported (rats/ } \\
\text { mice: kidney, liver, } \\
\text { spleen, intestines, } \\
\text { adrenal) }\end{array}$ & $\begin{array}{l}\text { Not reported } \\
\text { (in rats: } \\
\text { confirmed) }\end{array}$ & $\begin{array}{l}\text { Intracellularly by } \\
\text { phospholipase D }\end{array}$ & $\begin{array}{l}\text { Not excreted unchanged } \\
\text { (metabolised to } \\
\text { endogenous compounds) }\end{array}$ \\
\hline $\begin{array}{l}\text { Amphotericin } \\
\mathrm{B}^{\mathrm{a}}\end{array}$ & $\begin{array}{l}\text { D-AMB } \\
\text { L-AMB }\end{array}$ & IV & Liver, spleen & $\begin{array}{l}\text { Not reported } \\
\text { (in rats: } \\
\text { confirmed) }\end{array}$ & $\begin{array}{l}\text { Metabolism not } \\
\text { well-studied. } \\
\text { Liposomes } \\
\text { engulfed by RES }\end{array}$ & $\begin{array}{l}\text { D-AMB: urinary excretion } \\
(21 \%) \text {; faecal excretion } \\
(43 \%) \\
\text { L-AMB: urinary excretion } \\
(5 \%) \text {; faecal excretion } \\
(4 \%)\end{array}$ \\
\hline
\end{tabular}

CYP cytochrome $\mathrm{P} 450, \mathrm{D}-\mathrm{AMB}$ amphotericin B deoxylate, $I M$ intramuscular, $I V$ intravenous, $L$-AMB liposomal amphotericin B, RES Reticuloendothelial system

${ }^{a}$ More lipid formulations exist of amphotericin B, but these are outside the scope of this review 
Pharmacokinetics provide a scientific framework for choosing the appropriate (combination of) drugs and their dosage. The clinical pharmacokinetics of antileishmanial drugs, however, remain largely unexplored [6]. The aim of this review is to give a comprehensive overview of the pharmacokinetic characteristics relating to the absorption, distribution, metabolism and excretion (ADME) of systemically administered antileishmanial drugs currently being used in the clinic as a basis to further rationalise the therapy for leishmaniasis. Albeit the pharmacokinetics of miltefosine [7] and liposomal amphotericin B (L-AMB, with focus on treatment of fungal infections [8]) have previously been reviewed, our aim was to discuss the antileishmanial drugs collectively in the context of leishmaniasis.

We have composed a summary of all pharmacokinetic studies performed, providing the reported primary and secondary pharmacokinetic parameters in overview tables. The pharmacokinetics in special patient populations relevant in treatment of leishmaniasis are described: paediatric patients, HIV co-infected patients, pregnant patients and patients with renal failure. Furthermore, potential drugdrug interactions between antileishmanial drugs, as well as between antileishmanial and antiretroviral drugs are discussed. When information in humans is lacking, in vitro and in vivo animal studies are examined.

In this review we solely focus on systemically administered drugs, as the majority of these drugs are administered in both CL and VL. Topical formulations were omitted due to its sole applicability to CL patients. The systemic drugs included in this review (Table 1) are based on the World Health Organization (WHO) guidelines on Control of the Leishmaniases [2]: pentavalent antimony, paromomycin, pentamidine, miltefosine and AMB. In addition to these drugs, ketoconazole has been mentioned in systemic treatment of 'new world' CL species. Given the drug's limited clinical use and the decisions by the US Food and Drug Administration (FDA) and European Medicines Agency (EMA) to suspend its oral use in skin infections due to severe hepatotoxicity [9], ketoconazole is not discussed in this review.

With this review we aim to provide a more solid pharmacokinetic basis for a scientific approach to treatment design in future clinical studies investigating (combination) treatments against leishmaniasis. In addition, our aim was to identify knowledge gaps to guide future pharmacokinetic studies in this clinical area.

\section{Methods}

Pharmacokinetic studies were included in this review (Tables 2, 3, 4, 5, 6, 7) if pharmacokinetic parameters were reported in addition to drug concentrations.
Pharmacokinetic studies based on bio-assays were excluded due to low sensitivity and problems with potential comeasurements of the effect of metabolites. Many pharmacokinetic studies have been conducted for AMB, and for this reason we excluded studies with fewer than ten subjects or patients, studies with continuous infusion and studies on neonates $<3 \mathrm{~kg}$ based on their limited relevance in the context of the treatment of leishmaniasis. Studies on experimental formulations were excluded for all drugs, such as a pharmacokinetic study on the experimental generic sodium stibogluconate (SSG) formulation 'Ulamina' composed of the pentachloride of antimony plus $\mathrm{N}$ methylglucamine [10], as no records have been found of the commercialisation of this formulation.

\section{Absorption, Distribution, Metabolism and Excretion (ADME) and Clinical Pharmacokinetics}

\subsection{Pentavalent Antimonials}

Pentavalent antimonials (pentavalent $\mathrm{Sb} / \mathrm{Sb}^{\mathrm{V}}$ ) have been first-line treatment against $\mathrm{CL}$ and $\mathrm{VL}$ in the majority of endemic regions for decades, though increasing drug resistance has compromised its efficacy [3, 4]. Pentavalent antimonials are administered intramuscularly (IM) or intravenously (IV) in systemic treatment of both CL and VL. It is marketed in two formulations: SSG (marketed as Pentostam ${ }^{\circledR}$ ) and meglumine antimoniate (MA, marketed as Glucantime ${ }^{\circledR}$ ). The $\mathrm{Sb}$ content in the two antimonials is different with $85 \mathrm{mg} \mathrm{Sb} / \mathrm{mL}$ in MA and $100 \mathrm{mg} \mathrm{Sb} / \mathrm{mL}$ in SSG. Due to structural differences in these compounds, differences in pharmacokinetics could be expected. Unless indicated otherwise, results refer to SSG, as this is the most widely studied compound. All pharmacokinetic studies used analytical methods that do not distinguish between different chemical forms of antimony $\left(\mathrm{Sb}^{\mathrm{V}}\right.$, trivalent antimony $\mathrm{Sb}^{\mathrm{III}}$, etc.) [11]. The abbreviation $\mathrm{Sb}$ is used to refer to (total) antimony and will be used when discussing the results of the pharmacokinetic studies.

Despite being used in the clinic for decennia, the mechanism of action of $\mathrm{Sb}$ is not well-understood. Two main models currently exist: the pro-drug model and the active $\mathrm{Sb}^{\mathrm{V}}$ model. In the active $\mathrm{Sb}^{\mathrm{V}}$ model, $\mathrm{Sb}^{\mathrm{V}}$ has intrinsic antileishmanial activity finally leading to the inhibition of DNA topoisomerase I [12]. According to the pro-drug model, $\mathrm{Sb}^{\mathrm{V}}$ compounds are pro-drugs exerting its activity against the Leishmania parasite after reduction to $\mathrm{Sb}^{\mathrm{III}}$ in host cells [13]. $\mathrm{Sb}^{\text {III }}$ finally induces apoptosis by the activation of oxidative stress and increase of intracellular $\mathrm{Ca}^{2+}[12,14]$. Multiple studies have identified an indirect effect of $\mathrm{Sb}$ on immune activation (overview in Mookerjee Basu et al. [15]). The most 


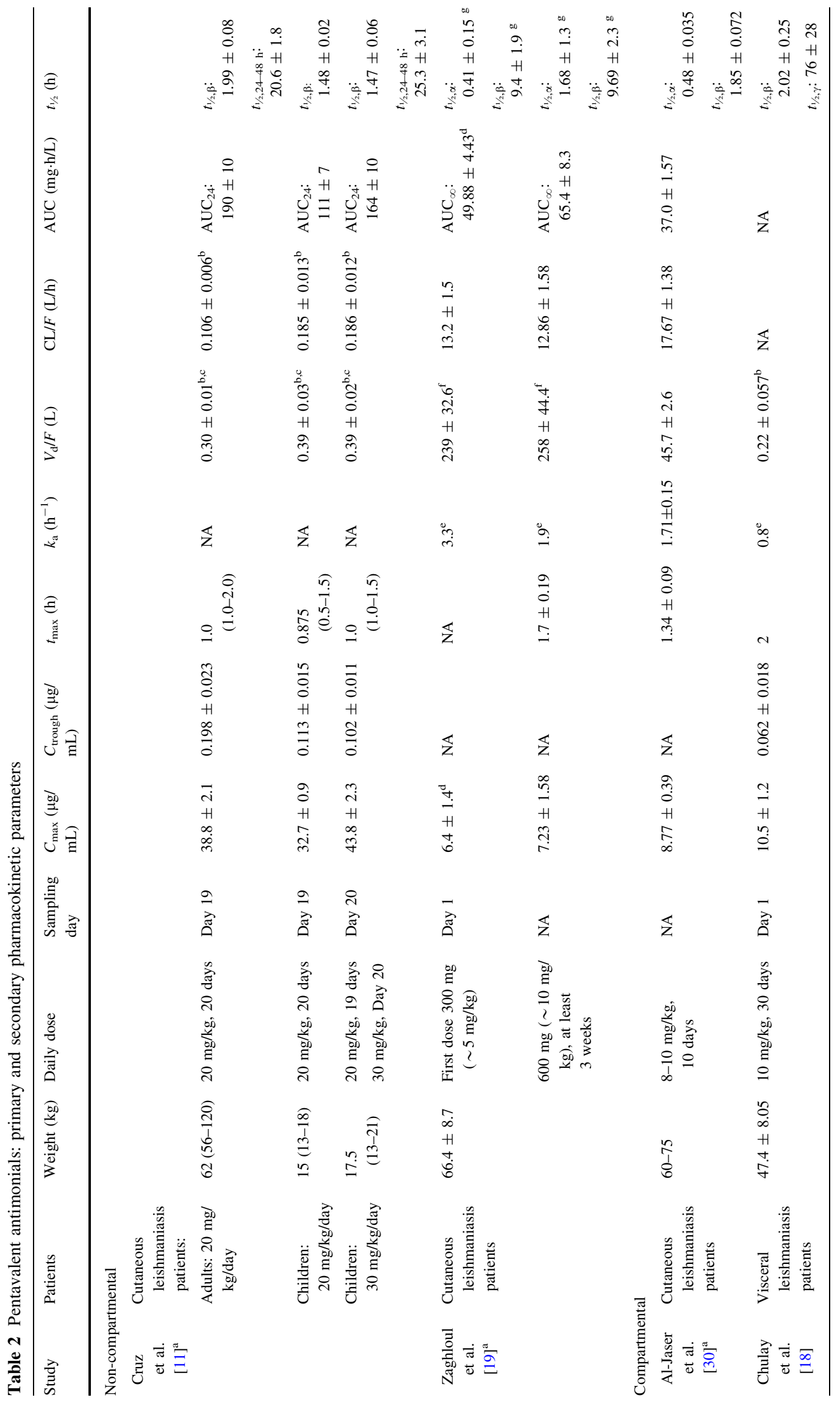




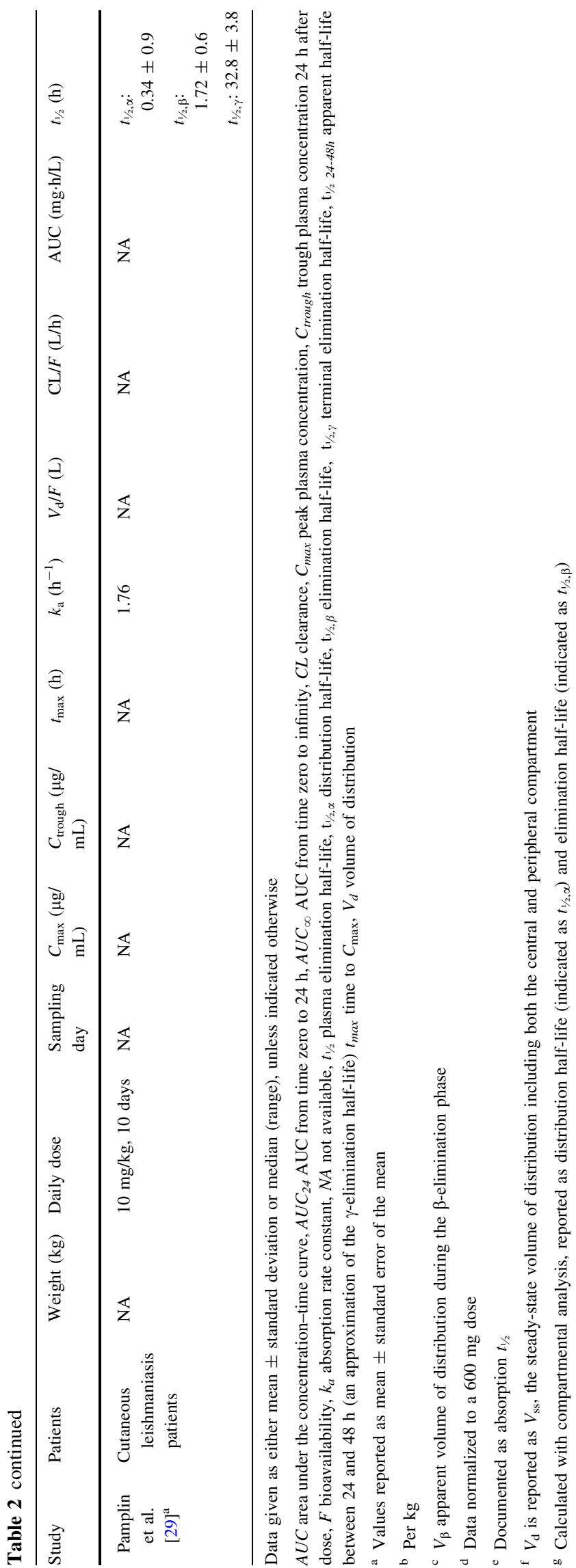

common adverse effects of treatment with pentavalent antimony are myalgia/arthralgia, gastrointestinal problems and headache [16]. In addition, serious adverse effects have been reported such as cardiomyopathy, renal failure and reversible hepatic and pancreatic abnormalities [16, 17].

\subsubsection{ADME}

After IM injection, $\mathrm{Sb}$ is absorbed quickly and the peak plasma concentration $\left(C_{\max }\right)$ is reached in between 0.5 and $2 \mathrm{~h}[11,18-20]$. Absorption half-lives $\left(t_{1 / 2}\right)$ varied between 0.36 and $0.85 \mathrm{~h}[18,19]$.

Highest accumulation of $\mathrm{Sb}$ in human volunteers, after administration of radioactively labelled $\left(\mathrm{Sb}^{124}\right)$ sodium antimony mercapto-succinate, was recorded in the liver $>$ thyroid $>$ heart [21]. A full $\mathrm{Sb}$ tissue distribution study in rhesus monkeys on day 55 after receiving a 21-day MA treatment showed highest $\mathrm{Sb}$ concentrations in the thyroid $>$ nails $>$ liver $>$ gall bladder $>$ spleen [22]. In rats, distribution at $24 \mathrm{~h}$ after a 21-day MA treatment was highest in the spleen $>$ kidney $>$ thyroid $>$ liver [23]. No protein binding data were reported.

$\mathrm{Sb}$ is administered systemically in treatment of CL and several studies have investigated skin $\mathrm{Sb}$ distribution. Al Jaser et al. [20] identified a small delay in distribution to the skin with a time to $C_{\max }\left(t_{\max }\right)$ of $2.1 \mathrm{~h}$ compared with $\sim 1.5 \mathrm{~h}$ for whole blood [20]. Skin biopsies taken from both the CL lesion and unaffected skin from patients treated with SSG $\sim 10 \mathrm{mg} / \mathrm{kg} /$ day for 10 days indicated no difference in $\mathrm{Sb}$ distribution to affected versus healthy skin (mean \pm standard error of the mean [SEM]: $C_{\max } 5.02 \pm 1.43$ and $6.56 \pm 2.01 \mu \mathrm{g} / \mathrm{g}$, respectively) [20]. Studies in Brazilian CL patients reported higher tissue concentrations with high variability after 20 days of $10-20 \mathrm{mg} \mathrm{Sb} / \mathrm{kg} /$ day (range $8.32-70.68 \mu \mathrm{g} / \mathrm{g}[24])$ and $20 \mathrm{mg} / \mathrm{kg} /$ day $(7.46 \pm 7.7 \mu \mathrm{g} / \mathrm{g}$ [25]). The wide spread in observed $\mathrm{Sb}$ tissue concentrations could possibly influence Sb efficacy in treatment of CL. However, no exposure-response studies were conducted in which skin exposure was related to treatment outcome.

The prevalent view is that $\mathrm{Sb}^{\mathrm{V}}$ derived from $\mathrm{Sb}^{\mathrm{V}}$-based drugs is reduced to $\mathrm{Sb}^{\mathrm{III}}$ intracellularly and subsequently released at slow rates, which partially explains the slow terminal elimination phase observed in total $\mathrm{Sb}$. Current pharmacokinetic studies have focused on the analysis of total $\mathrm{Sb}$ (Table 2), but Miekeley et al. [26] used inductively coupled plasma mass spectrometry (ICP-MS) to analyse $\mathrm{Sb}^{\mathrm{III}}$ and $\mathrm{Sb}^{\mathrm{V}}$ separately. They reported the first evidence for in vivo conversion of MA into ion species $\mathrm{Sb}^{\mathrm{V}}$ and $\mathrm{Sb}^{\mathrm{III}}$ in humans. In vitro, two locations have been identified where this bioreduction could take place: the acidic compartment of mammalian cells such as the phagolysosome in which the Leishmania parasite resides, or the cytosol of the parasite itself [27]. 


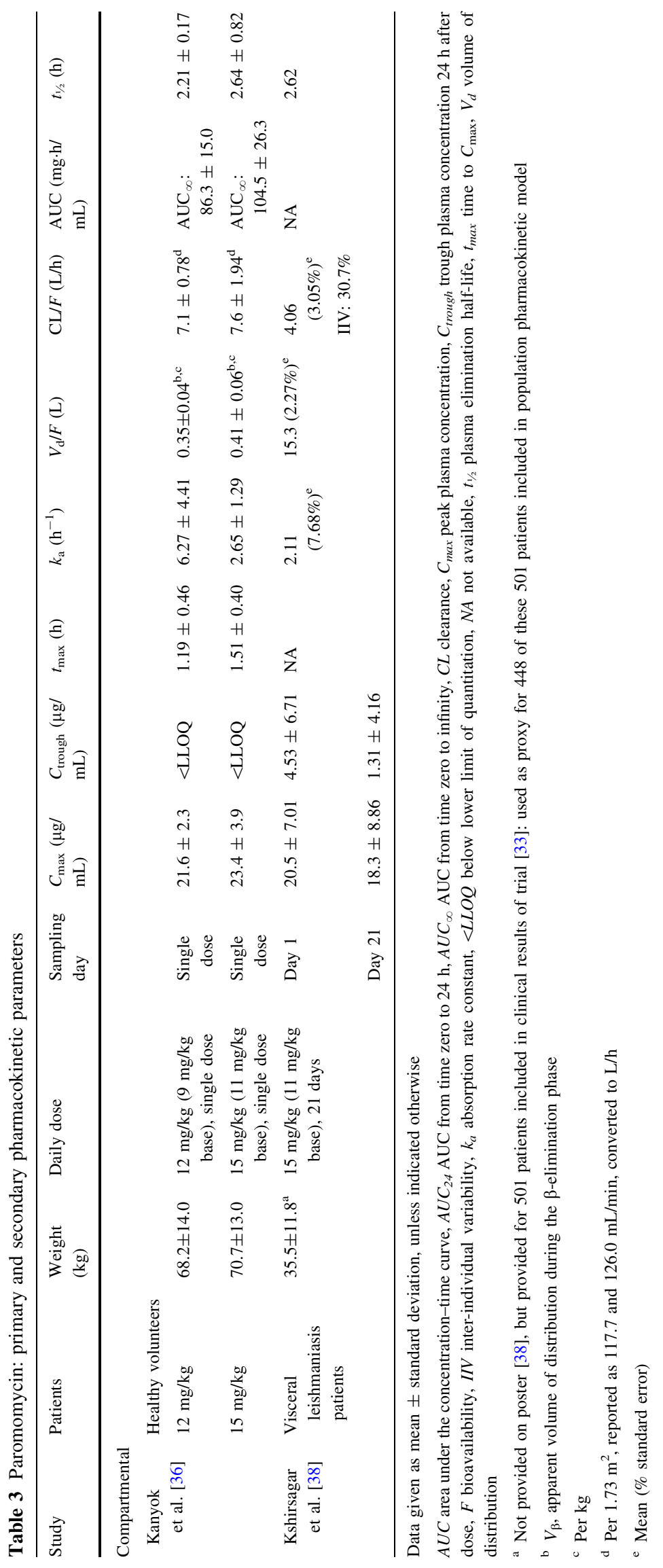




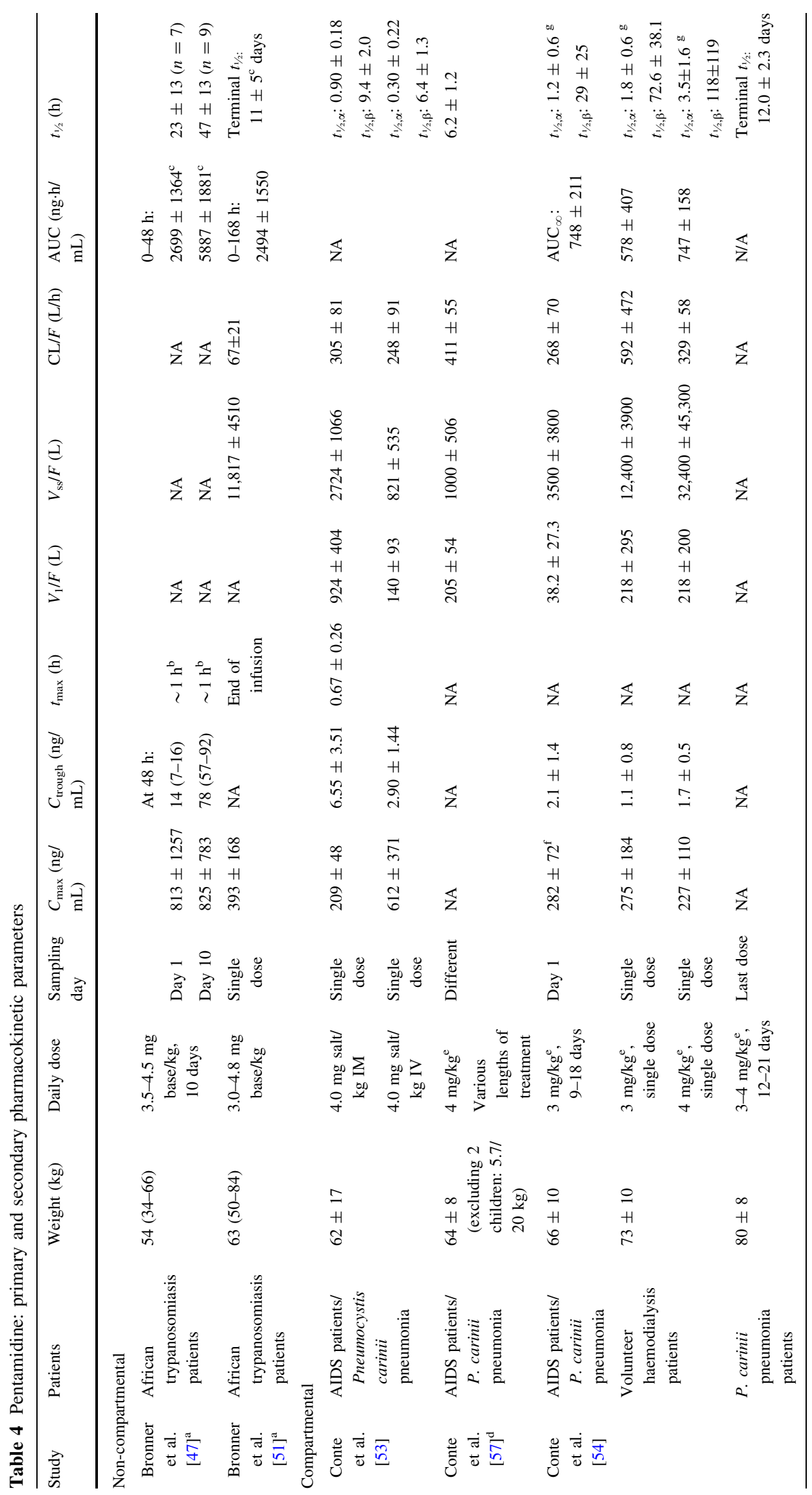


Given the ten-fold higher toxicity of $\mathrm{Sb}^{\mathrm{III}}$ species, the evaluation of $\mathrm{Sb}^{\mathrm{III}}$ pharmacokinetics could play an important part in evaluating adverse effects and therapeutic action. Whilst the $\mathrm{Sb}^{\mathrm{III}}$ content was negligible when analysing the drug in its formulation before administration, urine $\mathrm{Sb}^{\mathrm{III}}$ concentrations of $111 \mu \mathrm{g} / \mathrm{L}$ were observed 11 days after the last MA injection. Also in monkeys, the proportion of $\mathrm{Sb}^{\mathrm{III}}$ relative to total antimony increased from $5 \%$ on day 1 to $50 \%$ on day 9 , making it a major Sb plasma species during the slow terminal elimination phase [22].

Renal clearance is consistently documented to be the main route of $\mathrm{Sb}$ excretion and the adult weight-adjusted $\mathrm{Sb}$ clearance of $0.086-0.144 \mathrm{~L} / \mathrm{h} / \mathrm{kg}$ was in the same range as normal adult glomerular filtration rates $[11,28]$. The majority of $\mathrm{Sb}$ was eliminated via urine within $24 \mathrm{~h}$ after dosing with a short $t_{1 / 2}$ between 1.7 and $2.02 \mathrm{~h}[11,18,20,28,29]$. Between 40 and $80 \%$ of total dose given was retrieved in urine within $24 \mathrm{~h}$ of dosing $[19,30]$. The excess of the drug is excreted in nearly unaltered form in its formulation in complex with organic compound [26]. Significantly more rapid elimination could be observed in whole blood $\left(t_{1 / 2}=3.04 \mathrm{~h}\right)$ than in lesion tissue $\left(t_{1 / 2}=6.88 \mathrm{~h}\right)[20]$.

\subsubsection{Clinical Pharmacokinetics}

The pharmacokinetics of Sb (Table 2) administered IV or IM appeared to be similar: a two- or three-compartment model with bi-exponential elimination with short $t_{1 / 2} \mathrm{of}$ approximately $2 \mathrm{~h}$ and a terminal elimination phase of 1-3 days was found for both IV [29] and IM data [11, 18]. Miekeley et al. [26] —using the more sensitive ICP-MS for $\mathrm{Sb}$ analysis-reported an even slower terminal $t_{1 / 2}$ of $>50$ days, which could also be identified for monkeys (35.8 days) [22], hypothesised to be the intracellular conversion of $\mathrm{Sb}^{\mathrm{V}}$ to $\mathrm{Sb}^{\mathrm{III}}$, and subsequent slow release [18].

$C_{\max }$ varied between 7.23 and $10.5 \mu \mathrm{g} / \mathrm{mL}$ for a $10 \mathrm{mg} /$ $\mathrm{kg}$ daily dosing regimen $[18,19,30]$ and was $38.8 \mu \mathrm{g} / \mathrm{mL}$ in adults receiving a $20 \mathrm{mg} / \mathrm{kg}$ dose daily. This non-linearity could possibly be explained by differences in formulation, as Chulay et al. [18] reported a slightly higher $C_{\max }$ after MA administration $(11.2 \mu \mathrm{g} / \mathrm{mL}, n=3)$ than after SSG $(9.4 \mu \mathrm{g} /$ $\mathrm{mL}, n=2$ ). However, interpretation is difficult due to the small sample size. Another possible explanation for these observations could be the lower clearance observed in the Colombian CL population. There were no significant differences in pharmacokinetic parameters between a single dose and multiple dosing [19]. Pharmacokinetics appeared linear as the area under the concentration-time curve (AUC) from time zero to $24 \mathrm{~h}\left(\mathrm{AUC}_{24}\right)$ in children with a $50 \%$ increase in dose $(20-30 \mathrm{mg} / \mathrm{kg})$ increased $48 \%$ from 111 to $164 \mathrm{mg} \cdot \mathrm{h} / \mathrm{L}$ [11]. The $\mathrm{Sb}$ trough concentration $\left(C_{\text {trough }}\right)$ gradually increased around four-fold during a 20- to 30-day treatment $[11,18,28]$. 


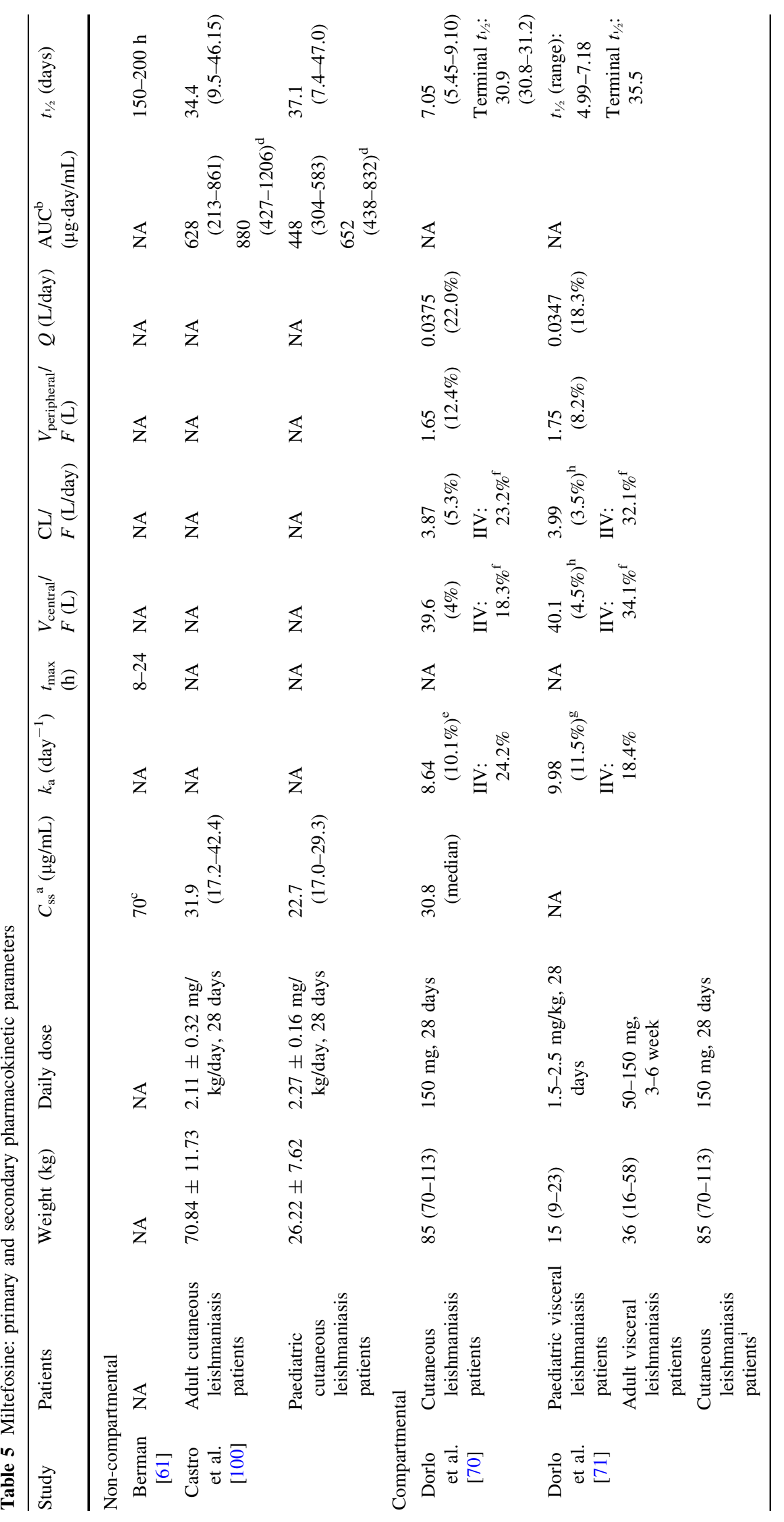




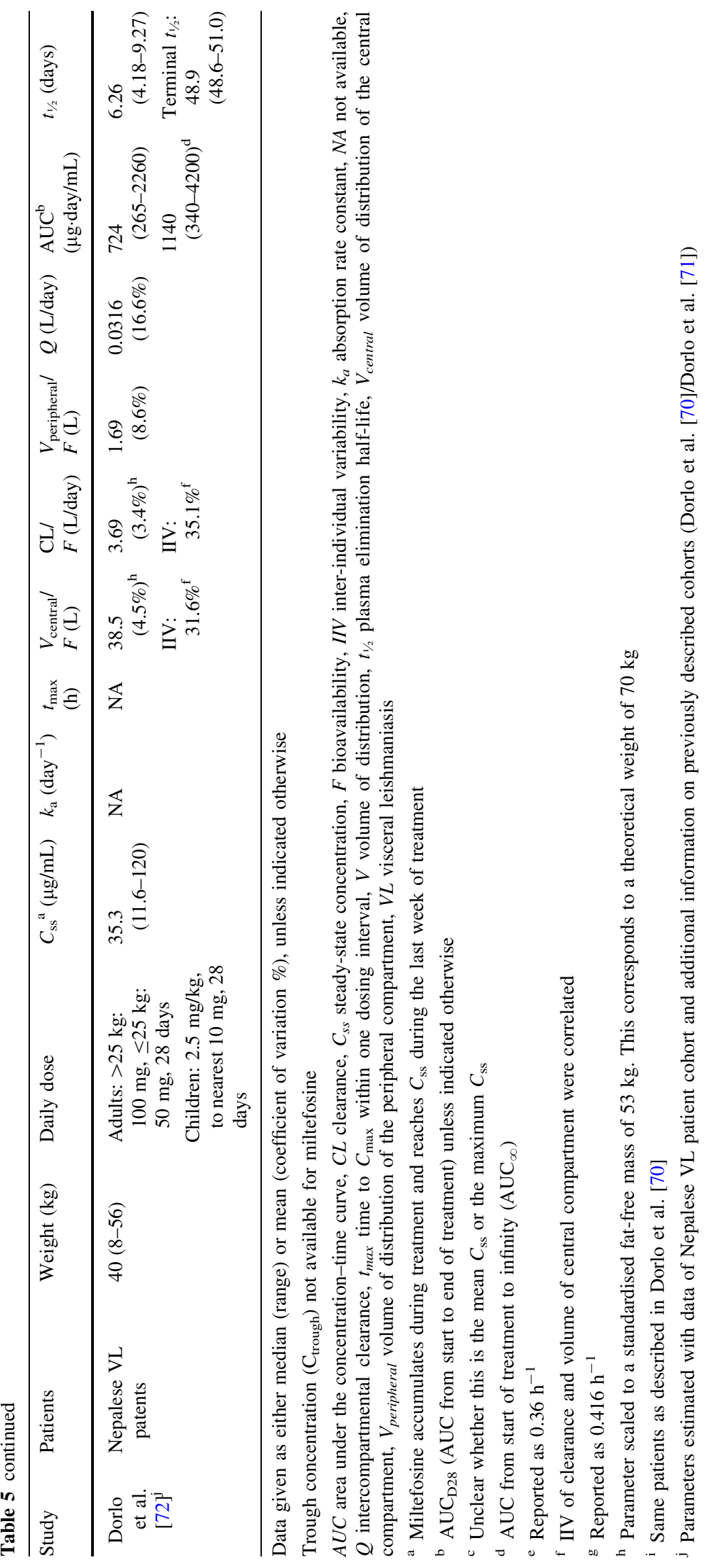




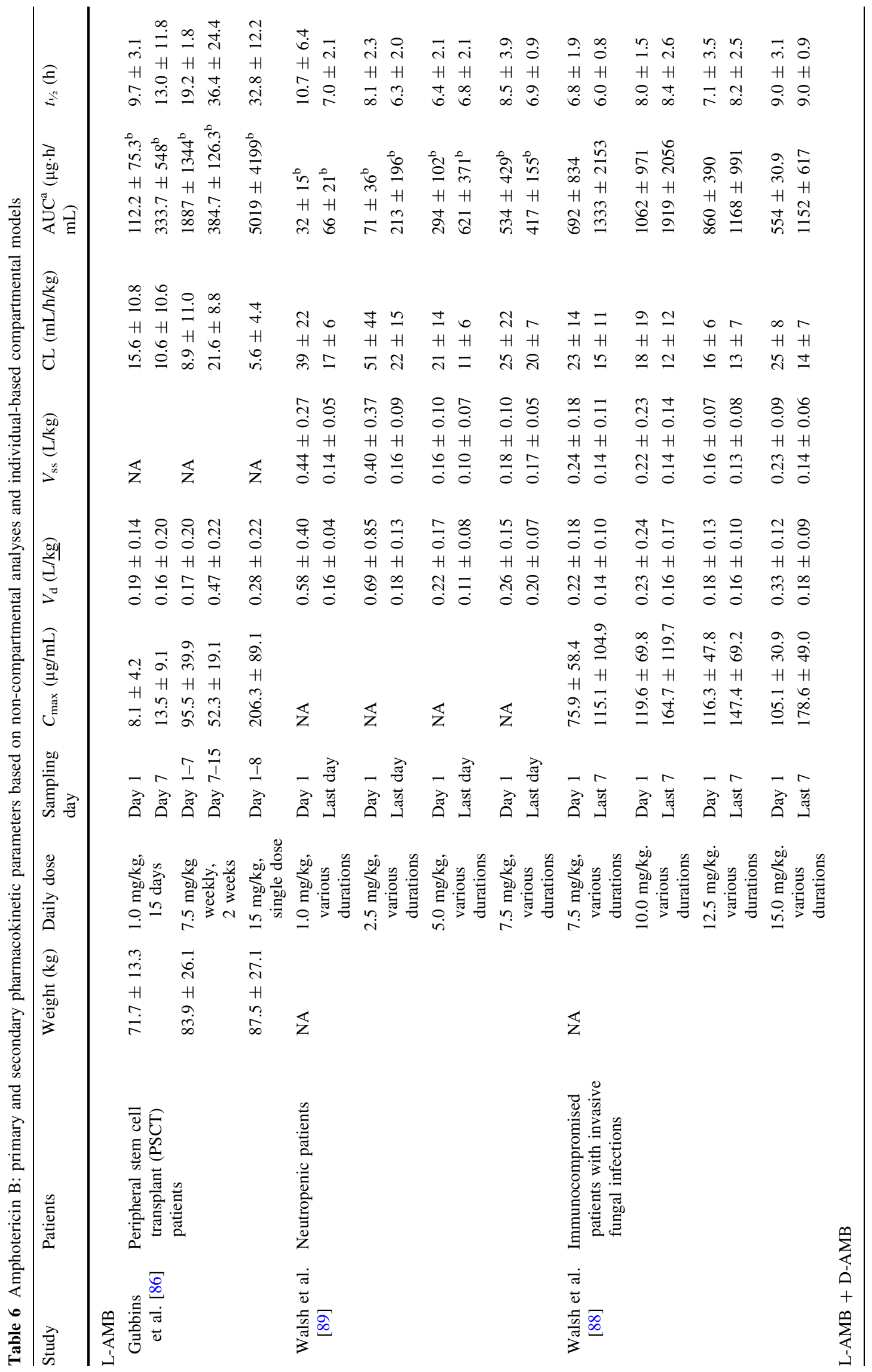




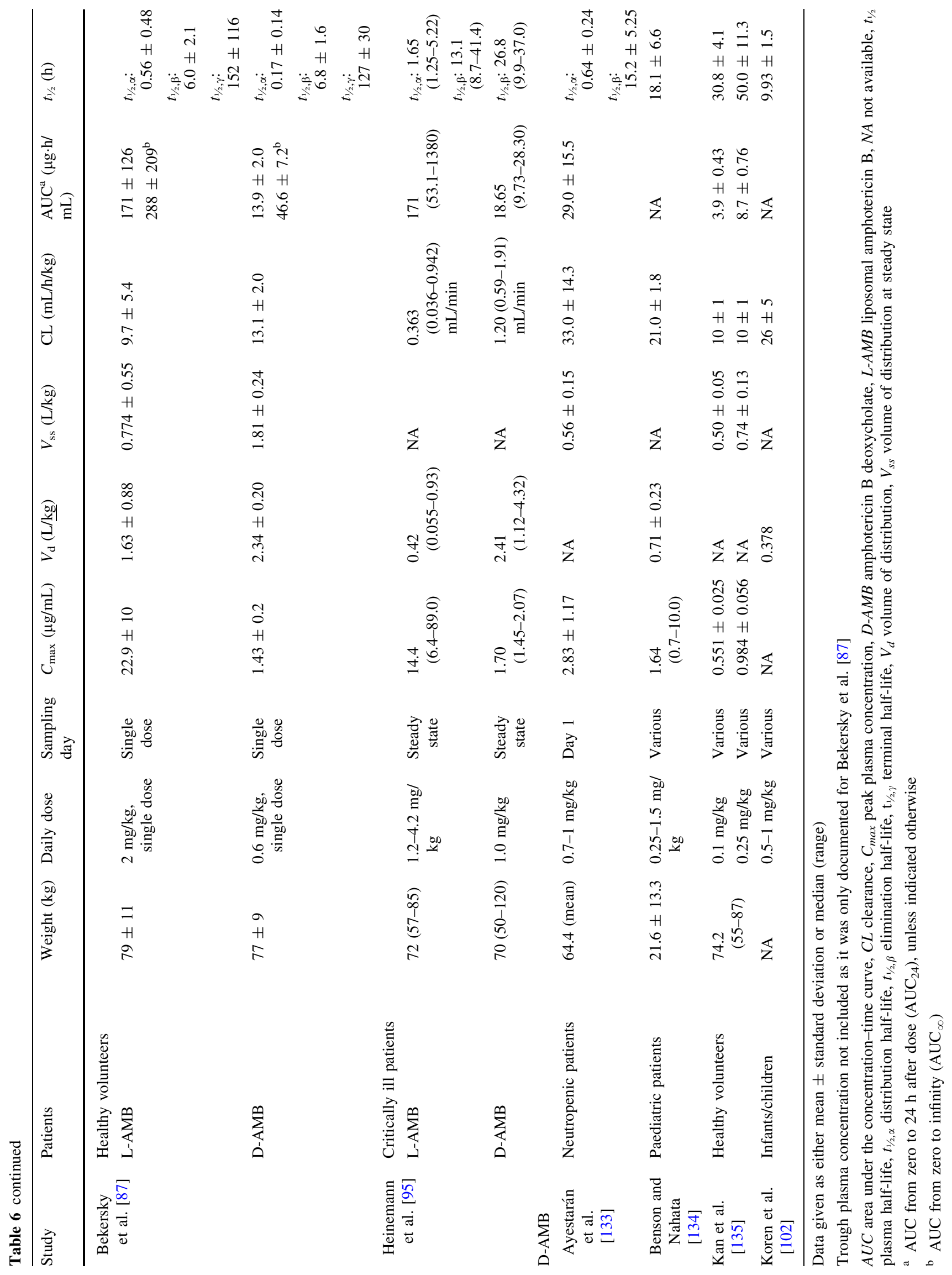




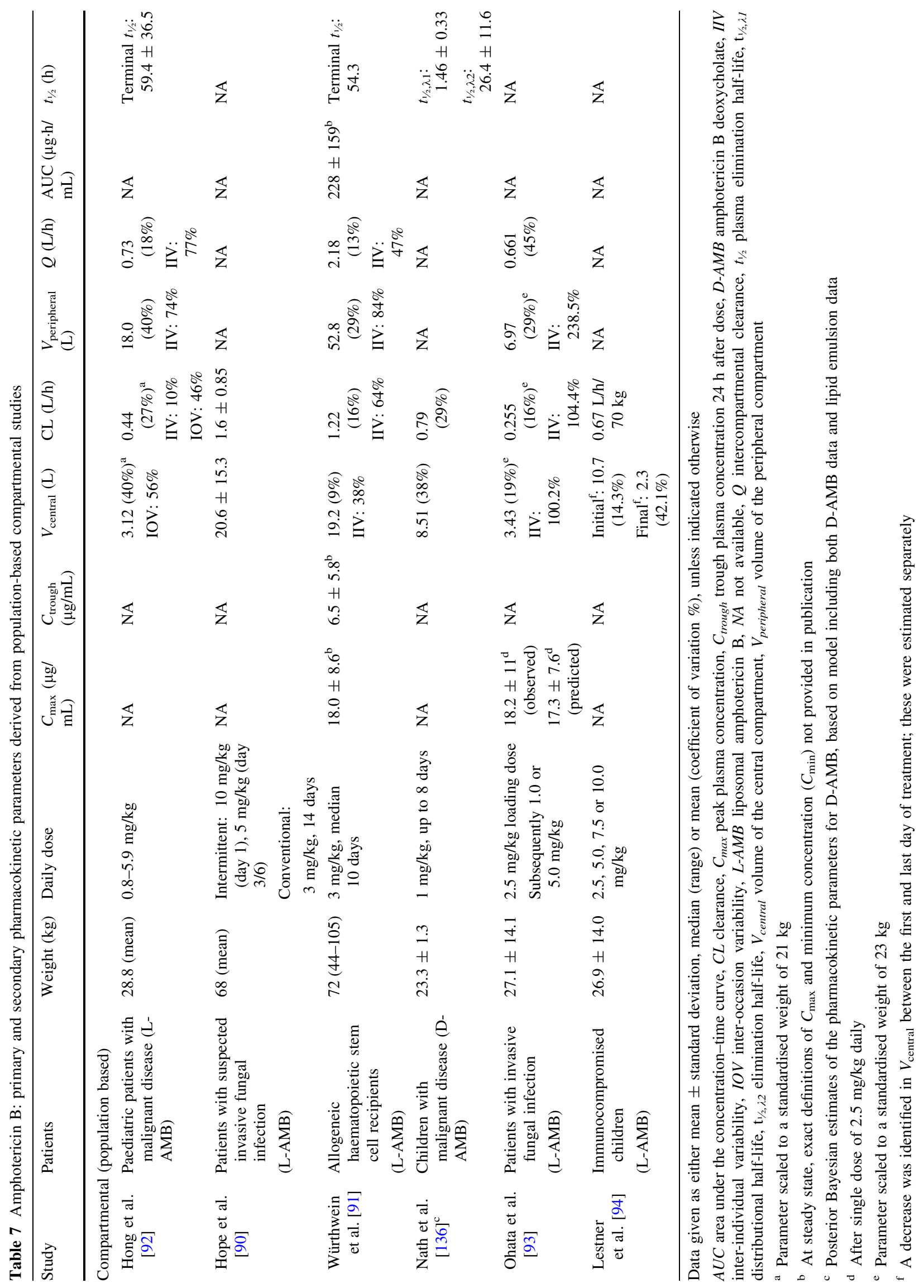


As mentioned previously, all pharmacokinetic studies used analytical methods that do not distinguish between different chemical forms of antimony ( $\mathrm{Sb}^{\mathrm{III}}, \mathrm{Sb}^{\mathrm{V}}$, etc.) [11]. $\mathrm{Sb}^{\mathrm{III}}$ is assumed to be the active component in Sb treatment in the pro-drug model. As only a small proportion of total $\mathrm{Sb}$ consists of $\mathrm{Sb}^{\mathrm{III}}$, total $\mathrm{Sb}$ might not accurately reflect the pharmacokinetics of antimonials, especially as inter-patient differences could be expected in the intracellular reduction to $\mathrm{Sb}^{\mathrm{III}}$. This accentuates the relevance of studying the intracellular pharmacokinetics of $\mathrm{Sb}$.

\subsection{Paromomycin}

Paromomycin, an aminoglycoside also known as aminosidine, is a highly hydrophilic and lipid insoluble antibiotic drug. Paromomycin is active against Gram-positive and Gram-negative bacteria, including Mycobacterium tuberculosis, and against some protozoa, including the Leishmania parasite. It is administered IM both as a monotherapy and as a shorter combination treatment together with SSG (reviewed in Davidson et al. [31]). Paromomycin is formulated as the salt paromomycin sulphate, of which approximately $75 \%$ consists of the base although sulphate salt contents vary per batch [32].

Paromomycin inhibits protozoan protein synthesis by binding to the $30 \mathrm{~S}$ ribosomal subunit resulting in the accumulation of abnormal 30S-50S ribosomal complexes and finally causing cell death. In the phase III clinical trial in Indian VL patients, the most common adverse effects were injection-site pain (55\%), rise in hepatic transaminases $(6 \%)$, ototoxicity (2\%) and renal dysfunction (1\%) [33].

\subsubsection{ADME}

Paromomycin is generally documented to be very poorly absorbed after oral administration [34, 35]. However, like other aminoglycosides, it is rapidly absorbed from IM injection sites and its absorption is nearly $100 \%$ [32]. The $t_{\max }$ is reached within 1 or $2 \mathrm{~h}$ after IM injection $[33,36,37]$. The absorption rate constant $\left(k_{\mathrm{a}}\right)$ was found to be $2.11-2.65 \mathrm{~h}^{-1}$ for a $15 \mathrm{mg} / \mathrm{kg}$ dose, but $6.27 \mathrm{~h}^{-1}$ for the $12 \mathrm{mg} / \mathrm{kg}$ dosing [36, 38], though variation in the latter is large [standard deviation (SD) of $4.41 \mathrm{~h}^{-1}$ ].

At physiological $\mathrm{pH}$, paromomycin is polar, which limits its distribution towards the intracellular fluids and tissues. In dogs, protein binding is limited to 4\% [39], similar to other aminoglycosides' binding in human serum [40]. Protein binding of paromomycin in humans is mostly stated to be negligible, though one study reported $33 \%$ protein-bound paromomycin [41]. The one-compartmental population pharmacokinetic model with low volume of distribution $\left(V_{\mathrm{d}}\right)$ of only 15.3 L that has been reported [38] is consistent with limited distribution and protein binding.
Paromomycin is not metabolised and is primarily excreted unchanged via glomerular filtration in the kidneys $[32,41,42]$, with a renal clearance of $101.0 \pm 16.5 \mathrm{~mL} /$ $\mathrm{min} / 1.73 \mathrm{~m}^{2}$ [36]. Elimination of paromomycin is fast: within 4 h over $50 \%$ of the dose could be detected in urine [36]. The $t_{1} / 2$ is between 2 and $3 \mathrm{~h}[36,38]$.

\subsubsection{Clinical Pharmacokinetics}

Two studies were performed on paromomycin pharmacokinetics (Table 3): one in healthy volunteers and one in a large population of Indian VL patients. Primary and secondary pharmacokinetic parameters were comparable between the two studies, indicating there were no specific disease effects of VL on the pharmacokinetics of paromomycin [36, 38].

$\mathrm{V}_{\mathrm{d}}$ was directly proportional to weight and was around $0.4 \mathrm{~L} / \mathrm{kg}$ for both studies [37, 39]. In the two studies, $C_{\max }$ was comparable (22-23 vs. $18-21 \mu \mathrm{g} / \mathrm{mL}$ ), without differences between males and females. A similar $C_{\max }$ (mean $\pm \mathrm{SD}$ ) was observed in healthy Sudanese subjects $(19.5 \pm 7.6 \mu \mathrm{g} / \mathrm{mL})$ [43]. Sudanese VL patients, however, had a much lower $C_{\max }$ of $5.6 \pm 4.2 \mu \mathrm{g} / \mathrm{mL}$ at $15 \mathrm{mg} / \mathrm{kg}$ and $7.8 \pm 4.9 \mu \mathrm{g} / \mathrm{mL}$ at $20 \mathrm{mg} / \mathrm{kg}$ [37]. This could imply differences in paromomycin pharmacokinetics in VL patients between regions, but interpretation is hampered by the small sample size in the Sudanese VL population $(n=9)$.

There were no significant differences in dose-adjusted AUC from time zero until infinity $\left(\mathrm{AUC}_{\infty}\right.$ ) between dosing groups $(12 \mathrm{mg} / \mathrm{kg}: 9.29 \pm 1.52 \mathrm{mg} \cdot \mathrm{h} / \mathrm{L}$ per $\mathrm{mg} / \mathrm{kg} ; 15 \mathrm{mg} /$ $\mathrm{kg}: 9.29 \pm 2.2 \mathrm{mg} \cdot \mathrm{h} / \mathrm{L}$ per $\mathrm{mg} / \mathrm{kg}$ ), indicating linear pharmacokinetics at these dose levels [36]. There was no evidence of drug accumulation or induction of metabolism upon multiple dosing [33]. $C_{\text {trough }}$, however, declined from $4.53 \pm 6.71 \mu \mathrm{g} / \mathrm{mL}$ on day 1 to $1.31 \pm 4.16 \mu \mathrm{g} / \mathrm{mL}$ on day 21, but with high variation [33].

The site of action of paromomycin is intracellular and resistance of parasites against paromomycin was found to be related to decreased drug uptake in resistant compared with wild-type strains [44]. This affirms the importance of evaluating intracellular pharmacokinetics of paromomycin in future pharmacokinetic studies.

\subsection{Pentamidine}

Pentamidine is a synthetic derivative of amidine, which was used to treat refractory VL in India in the 1980s. Since then it has been used as a second-line therapy against leishmaniasis, but has mainly been administered for treatment of sleeping sickness and Pneumocystis carinii (now known as $P$. jerovicii) infections in AIDS patients. The drug is given by IM or, preferably, IV administration. In 
the past, two lyophilised salts of pentamidine were marketed. However, since the $1990 \mathrm{~s}$ the production of pentamidine dimesylate ceased while pentamidine isethionate remained, which contains $1 \mathrm{~g}$ of base per $1.74 \mathrm{~g}$ of salt. As both formulations are salts dissolved in water, no differences were expected in their pharmacokinetics.

The mechanism of action of pentamidine is unclear, but the mitochondrion was found to be an important target of pentamidine action [45]. The use of pentamidine in treatment against leishmaniasis is mainly limited by its severe adverse effects: diabetes mellitus, severe hypoglycaemia, shock, myocarditis and renal toxicity [2].

\subsubsection{ADME}

Due to the two strongly basic amidine groups, oral bioavailability of pentamidine is low [46]. Therefore, pentamidine is administered IV or IM in treatment of leishmaniasis. The $t_{\max }$ after IM injection is approximately $1 \mathrm{~h}$ [47].

The distribution of pentamidine was studied in biopsies of 22 deceased AIDS patients [48]. Organs with the highest accumulated pentamidine concentrations were the kidney, liver, spleen and adrenal glands. Radiolabelled pentamidine in humans is rapidly taken up by the liver: $2.5 \mathrm{~h}$ after commencement of IV infusion, $65 \%$ of the drug could be traced to the liver [49]. Pentamidine seemed to be excreted in bile, but the release from the liver is slow: $99 \%$ of the absorbed pentamidine in the liver is still present $24 \mathrm{~h}$ after IV infusion [49]. Pentamidine is approximately $70 \%$ protein bound.

Pentamidine was extensively metabolised in isolated perfused rat liver [50]. In vitro cytochrome P450 (CYP) enzymes CYP2D6 and CYP1A1 were responsible for pentamidine metabolism in human liver microsomes [51]. Involvement of CYP1A1 in pentamidine metabolism was later confirmed in human liver microsomes, with additional involvement of CYP3A5 and CYP4A11, but involvement of CYP2D6 could not be identified [52]. No data could be found on pentamidine metabolites in humans [52].

Multiple studies found a low urinary excretion of pentamidine of between 2.1 and $5.5 \%$ or below $20 \%$ in the first $24 \mathrm{~h}$ after infusion [49, 53-55]. Faecal excretion was found to be only one-third of the amount excreted in urine [56].

\subsubsection{Clinical Pharmacokinetics}

Pentamidine pharmacokinetics are best described by twoor three-compartment models (Table 4). A rapid distribution phase was observed with a sharp $32 \%$ plasma concentration decrease within 10 min after end of infusion $\left(t_{1 / 2} \sim 5 \mathrm{~min}\right)[51,54]$.
Pentamidine pharmacokinetics have most extensively been studied in the 1980s and 1990s in heterogeneous patient populations. As can be seen from Electronic Supplementary Material Table 3, included patients are often a mixture of male/female, child/adult, with/without renal failure, dialysis/no dialysis and AIDS patients/non-AIDS patients, with different dosages and sampling schemes. This possibly explains the wide variability in reported pharmacokinetic parameters. Regardless of the high variability, a consistently large $V_{\mathrm{d}}$ was observed, consistent with $70 \%$ protein binding. There is a large variability in the documented elimination $t_{1 / 2}$ of pentamidine, but a consistent 11- to 12-day terminal $t_{1 / 2}$ was found [51, 54] (Table 4). Pentamidine accumulates during treatment $[47,54,57,58]$ and pre-dose $C_{\text {trough }}$ levels increased from 14 to $78 \mathrm{ng} / \mathrm{mL}$ during a 10-day once-daily treatment [47].

It is widely assumed that the Leishmania infection inhibits hepatic drug metabolism, which was found to be mediated by nitric oxide in hamsters [59]. This could possibly affect pentamidine exposure in VL patients, as pentamidine is metabolised by CYP enzymes. However, to our knowledge, the pharmacokinetics of pentamidine have never been investigated in VL patients.

\subsection{Miltefosine}

Miltefosine is an alkylphosphocholine drug with a polar head and hydrophobic tail and a critical micelle concentration of approximately $20 \mu \mathrm{g} / \mathrm{mL}(50 \mu \mathrm{mol} / \mathrm{L})$ [60]. Though originally developed as an anti-cancer drug, it has been licensed since 2002 in India for VL treatment and since 2004 in Germany for treatment of CL.

No definite mode of action is determined for miltefosine, but multiple hypotheses have emerged, such as induction of apoptosis, disturbance of lipid-dependent cell signalling pathways, alteration of membrane composition and immunomodulatory effects [7]. Miltefosine is orally administered in standard treatment of $2.5 \mathrm{mg} / \mathrm{kg}$ daily for 28 days and this is well-tolerated with mainly gastrointestinal adverse effects.

\subsubsection{ADME}

Miltefosine is slowly absorbed upon oral administration. The $k_{\mathrm{a}}$ is approximately 9 days $^{-1}$, which corresponds to an absorption $t_{1 / 2}$ of $\sim 2 \mathrm{~h}$. The $t_{\max }$ was reported to be between 8 and $24 \mathrm{~h}$ [61]. In East-African VL patients, absorption appeared to be even slower, indicating a possible disease effect on the absorption of miltefosine (Dorlo et al., unpublished data). Bioavailability in rats and dogs was found to be 82 and 94\%, respectively [7]. No data are available in humans, due to the haemolytic activity of miltefosine after IV infusion [62, 63]. 
Pre-clinical in vivo studies in mice and rats indicated a wide distribution of miltefosine and uptake in a range of different tissues. In rats, $\left[{ }^{14} \mathrm{C}\right]$-radioactively labelled miltefosine was predominantly found in the kidney $>$ intestinal mucosa $>$ liver $>$ spleen [64]. Another study in rats showed similar distribution patterns after 18 days of oral miltefosine administration (kidney $>$ adrenal $>$ skin $>$ spleen $>$ small intestines) [65]. Radiolabelled miltefosine oral administration in mice resulted in accumulation in the kidney $>$ liver $>$ lung [66].

In humans, plasma protein binding was 96-98\%, of which $97 \%$ bound to albumin [62]. Miltefosine accumulated in peripheral blood mononuclear cells (PBMCs), with an approximately two-fold higher PBMC than plasma concentration [67]. A $0.4 \mu \mathrm{g} / \mathrm{mL}$ miltefosine cerebrospinal fluid (CSF) concentration was measured after 5 days of miltefosine treatment in patients with granulomatous amoebic encephalitis, suggesting a $2-4 \%$ miltefosine passage across the blood-brain barrier, although integrity of the barrier could not be guaranteed [68].

An in vitro evaluation of 15 different CYP enzymes revealed no oxidative metabolism of miltefosine [7, 61] and no CYP3A isoenzyme induction was observed in vivo in rats [61]. Instead, miltefosine is most probably metabolised intracellularly by phospholipase D [64, 66]. No metabolic conversion of miltefosine was observed by phospholipases A and B [64], and metabolism by phospholipase $C$ is still debated $[64,66]$. After IV infusion with radioactive miltefosine in mice, most radioactivity in the liver was attributable to unchanged miltefosine (63\%), with the main breakdown product being choline $(32 \%)$, with low levels of phosphocholine (3\%) and 1,2-diacylphosphatidylcholine (2\%) [66].

The breakdown products of miltefosine are abundant endogenous compounds and are therefore difficult to quantify, e.g. choline is involved in the biosynthesis of cell membranes. There is little excretion of unchanged miltefosine; excretion of miltefosine in urine accounts for only $<0.2 \%$ of the administered dose at day 23 of treatment [61]. Faecal elimination has not been evaluated in humans, but slow faecal elimination of $10 \%$ of total miltefosine excretion has been reported in Beagle dogs [69].

\subsubsection{Clinical Pharmacokinetics}

In contrast to older antileishmanial drugs, the pharmacokinetics of miltefosine have been studied more intensively (Table 5). The first reported population pharmacokinetic model of miltefosine identified a long terminal elimination phase with a $t_{1 / 2}$ of 31 days [70], in addition to the initially reported 7-day elimination $t_{1 / 2}[61]$.
Due to this long $t_{1 / 2}$, miltefosine accumulates during treatment to finally reach steady-state concentrations approximately in the last week of the 28-day treatment. In a more extensive population pharmacokinetic model, including data on both adult and paediatric patients with CL or VL, differences between patients in $V_{\mathrm{d}}$ and clearance could best be described by allometrically scaling these parameters by fat-free mass [71]. A lower exposure was found for children than for adults while receiving the same $2.5 \mathrm{mg} / \mathrm{kg}$ dose (see Sect. 4.1).

To date, only one study has been published on the relationship between exposure and response in antileishmanial therapies [72]. A 1-day decrease in the time the miltefosine plasma concentration was above the $10 \times \mathrm{EC}_{50}$ (mean half-maximal effective concentration), compared with the median of 30 days, was associated with a 1.08-fold increase in odds of treatment failure in VL [72]. Miltefosine has been found to accumulate intracellularly in PBMCs, which could influence miltefosine exposure at its site of action, though no significant correlation could be identified with treatment outcome in a non-compartmental analysis [67].

\subsection{Amphotericin B}

AMB is a polyene antifungal, is poorly soluble in water and has a high affinity for sterol-containing membranes. The two main formulations are AMB deoxylate (D-AMB) and liposome encapsulated AMB (L-AMB). D-AMB was developed in the $1950 \mathrm{~s}$ and has been widely administered as an antifungal drug for the treatment of invasive fungal infections, but its dose-limiting nephrotoxicity and hypokalaemia hampers its use in the clinic. The lipid formulation L-AMB, incorporating $\mathrm{AMB}$ in a liposome bilayer, significantly reduced its renal toxicity and infusion-related toxicity. AMB binds to ergosterol in the cell membrane, subsequently leading to pore formation, fluid leakage and cell death. L-AMB adverse effects are mild infusion reactions and transient nephrotoxicity or thrombocytopenia.

Other lipid-based formulations of $\mathrm{AMB}$ exist such as AMB lipid complex (ABLC; Abelcet ${ }^{\circledR}$ ) or AMB colloidal dispersion (ABCD; Amphocil ${ }^{\mathrm{TM}} / \mathrm{Amphotec}^{\circledR}$ ). In this review we only focus on L-AMB (AmBisome ${ }^{\circledR}$ ), since this is the most widely used lipid AMB formulation in leishmaniasis. Any findings regarding L-AMB cannot be extrapolated to other lipid formulations of AMB, as substantial differences exist in pharmacokinetic parameters between these formulations [8, 73].

$\mathrm{AMB}$ exists in different forms in the plasma: proteinbound AMB, free AMB and, upon L-AMB administration, 
also liposome-associated AMB. To date, all but one of the pharmacokinetic studies only determined the total AMB concentration after destruction of the liposome with organic solvent and subsequent release of AMB. If not clarified otherwise, the abbreviation AMB refers to total AMB.

\subsubsection{ADME}

AMB is poorly absorbed after oral administration, due to the hydrophobicity of its polyene structure. Daily dosages of $2-5 \mathrm{~g}$ resulted in (subtherapeutic) systemic concentrations of below $0.5 \mu \mathrm{g} / \mathrm{mL}$ (reviewed in Janknegt et al. [74]).

AMB is highly protein bound ( $>90 \%$ ) [75]. In vitro binding in human plasma, determined by ultrafiltration, showed that $95-99.5 \%$ of AMB was bound in plasma, with increasing percentages bound with increasing AMB concentrations [76].

Interestingly, a physiologically based pharmacokinetic model has recently been developed describing the biodistribution of $\mathrm{AMB}$ in tissues of mouse, rat and human [77]. To describe the data well, a saturable uptake of AMB in reticuloendothelial system organs, such as the VL target sites spleen and liver, was required. Predicted human tissue data were in good correspondence with autopsy data from patients who received L-AMB therapy [78]. In three autopsy cases, highest AMB concentrations (after a total dose of $820-3428 \mathrm{mg}$ ) were observed in the liver $(92.8-291 \mu \mathrm{g} /$ g) and spleen (150-291 $\mu \mathrm{g} / \mathrm{g})$, with lower concentrations in the kidney, thyroid, bone marrow and lung $(<50 \mu \mathrm{g} / \mathrm{g})$ [78]. Of the administered dose, $13.9-22.5 \%$ could be recovered from the liver [78]. This was in line with a larger autopsy study with seven L-AMB treated patients, where highest concentrations were found in the liver $(102.81 \pm 68.72 \mu \mathrm{g} / \mathrm{g})$ and spleen $(60.32 \pm 29.75 \mu \mathrm{g} / \mathrm{g})$ [79]. CSF levels were approximately 1000-fold lower than concurrent serum levels [80]. Similar distribution patterns were observed after treatment with D-AMB [81], with highest accumulation in liver (up to $188 \mu \mathrm{g} / \mathrm{g}$ ) and spleen (up to $190 \mu \mathrm{g} / \mathrm{g}$ ) [81]. In total, $14-41 \%$ of the administered dose could be recovered from the liver (with a total maximum recovery of 51\%) [81].

The same distribution (spleen and liver $>$ kidneys $>$ lungs) was also found in mice [82, 83]. AMB concentrations were significantly lower in the liver and spleen of VLinfected mice than in non-infected mice, hypothesised to be due to a loss in phagocytic activity in infected macrophages [84]. Disruption of normal liver function in VL might thus affect AMB exposure in VL patients.

D-AMB skin concentrations in rats were $30-50 \%$ of plasma concentrations and show a decrease over time parallel to these plasma concentrations [85]. Upon L-AMB administration, buccal mucosal AMB concentrations rise to concentrations 6-47 times higher than plasma concentrations [86].

Metabolism of AMB has not been well-studied and metabolites have up to now not been identified [74]. Preclinical studies reported that AMB is eliminated from the circulation by the urinary and biliary tract and by the reticuloendothelial system, the latter of which is also responsible for the clearance of L-AMB from the circulation (reviewed in Gershkovich et al. [84]). One week after a single dose, urinary excretion of unchanged AMB was 20.6 and $4.5 \%$ for D-AMB- and L-AMB-treated subjects, respectively [87]. During the same period, faecal excretion was $42.5 \%$ for D-AMB-treated subjects but only $4 \%$ for subjects treated with L-AMB. Possible explanations for the decrease in excretion of unchanged AMB in the liposomal formulation could either be a change in distribution of the $\mathrm{AMB}$, prolongation of its residence time or increased metabolism.

\subsubsection{Clinical Pharmacokinetics}

The pharmacokinetics of L-AMB, best described by a twoor three-compartment model, have been studied in a wide range of dosages (Tables 6,7 ), but has never been evaluated in leishmaniasis patients.

Variability (coefficient of variation [CV\%]) in pharmacokinetic parameters was much higher for L-AMB than for D-AMB ( $\mathrm{AUC}_{24} \mathrm{CV} \%$ of 73.4 and $14.4 \%$, respectively) [87]. High variability in AMB exposure could potentially be caused by differences in the uptake of liposomes into non-blood compartments, or differences in drug release from the carrier liposomes. Interestingly, variability in exposure decreased with higher dosages, e.g. $C_{\max } \mathrm{CV} \%$ decreased from 91 to $27 \%$ with increased dosing from 7.5 to $15 \mathrm{mg} / \mathrm{kg}$, respectively [88].

Linear pharmacokinetics were reported up to a $7.5 \mathrm{mg} /$ $\mathrm{kg}$ dose. At higher dosages, time-dependent non-linear L-AMB pharmacokinetics have been described [88, 89]. Evaluating L-AMB dosages of $7.5-15.0 \mathrm{mg} / \mathrm{kg}$, the highest $C_{\max }$ and AUC levels were reached at $10 \mathrm{mg} / \mathrm{kg}$, implying that (alternative) elimination mechanisms are induced or activated above this concentration [88]. Possibly, the uptake by the reticuloendothelial system is enhanced, which would simultaneously explain the high AMB concentration in the liver, spleen and bone marrow [88].

Considering these non-linearities and the high variability in pharmacokinetic parameters between patients, a non-compartmental analysis or individual-based compartmental analysis would not be appropriate to capture the pharmacokinetic profile of L-AMB. Five multi- 
compartmental population pharmacokinetic models have been developed for L-AMB [90-94]. The median weight in these studies varies widely (Electronic Supplementary Material Table 5), since multiple studies only included paediatric patients $[92,93]$. Interestingly, a recent study reported a decrease in the $V_{\mathrm{d}}$ over time during treatment [94]. Furthermore, body weight has been identified as a covariate on clearance and $V_{\mathrm{d}}$ in most modelling studies [90, 92-94], often allometrically scaled [92, 94]

For most patients, $C_{\text {trough }}$ values increased $\sim 2.6$-fold following multiple administrations, but for a portion of patients the increase was above ten-fold (exact treatment duration not reported) [93]. Walsh et al. [89] did not find an increase in $C_{\text {trough }}$ after repeated dosing.

Encapsulation of AMB in liposomes alters the pharmacokinetics of the drug. A lower clearance and a lower $V_{\mathrm{d}}$ was reported for L-AMB compared to D-AMB [87, 95]. The $C_{\max }$ (mean $\pm \mathrm{SD}$ ) of unbound $\mathrm{AMB}$ was significantly lower for patients treated with $2 \mathrm{mg} / \mathrm{kg}$ of L-AMB $(0.016 \pm 0.004 \mu \mathrm{g} / \mathrm{mL})$ than for patients treated with $0.6 \mathrm{mg} / \mathrm{kg}$ of D-AMB $(0.060 \pm 0.01 \mu \mathrm{g} / \mathrm{mL}) \quad$ [76], explaining the decrease in adverse effects after L-AMB administration compared with D-AMB. Unbound AMB elimination was biphasic with a longer $t_{1 / 2}$ than total AMB (initial $t_{1 / 2}$ of $7.7 \pm 2.8 \mathrm{~h}$, terminal $t_{1 / 2}$ of $467 \pm 372 \mathrm{~h}$ [76]).

All AMB pharmacokinetic studies conducted were performed in often immunosuppressed patients with fungal infections and no study has been conducted in leishmaniasis patients to date. As the spleen and liver physiology is severely damaged in VL, the uptake of L-AMB by the reticuloendothelial system might be altered, possibly changing the pharmacokinetics of AMB in VL patients. Furthermore, AMB pharmacokinetics have only been evaluated in plasma. Analysing the intracellular AMB pharmacokinetics might give more reliable information on the AMB exposure of the parasite at the site of action.

\section{Specific Patient Populations}

\subsection{Paediatric Patients}

Evaluation of the pharmacokinetics of antileishmanial drugs in the paediatric patient population is of particular importance, since $45 \%$ of the global leishmaniasis incidence consists of children under the age of 15 years old [96]. However, in the clinical development of antileishmanial drugs, pharmacokinetic studies in children have often been omitted. Children mostly receive the same $\mathrm{mg} /$ $\mathrm{kg}$ dosing regimen as adults, although it is generally accepted that this leads to lower exposure in children as clearance and $V_{\mathrm{d}}$ are allometrically scaled by weight or fatfree mass [97]. For Sb, paromomycin, miltefosine and $\mathrm{AMB}$, additional studies have been performed to gain more insight into the pharmacokinetics in children and to rationalise dosing in this vulnerable patient population. However, while differences in exposure between adult and paediatric patients were observed for $\mathrm{Sb}$, miltefosine and AMB, specific paediatric dosages are currently only clinically being evaluated for miltefosine.

Children are relatively underexposed to miltefosine in comparison with adults (Sect. 3.5) and have a higher risk of relapse [71, 72, 98-100]. With a conventional linear 28-day $2.5 \mathrm{mg} / \mathrm{kg}$ daily dosing, only $71.4 \%$ of children reached an AUC from day zero to day 28 of treatment $\left(\mathrm{AUC}_{\mathrm{D} 28}\right)$ of $412 \mu \mathrm{g}$ day $/ \mathrm{mL}$, while $90 \%$ of adults reached this threshold [71]. Simulating a 28-day allometric dose regimen, where low-weight patients would receive a higher $\mathrm{mg} / \mathrm{kg}$ daily dose, 95.6 and $97.3 \%$ of adults and children reached an $\mathrm{AUC}_{\mathrm{D} 28}$ of $412 \mu \mathrm{g}$ day/mL [71]. This allometric dose is currently being evaluated in paediatric VL patients aged 4-12 years old in Kenya and Uganda (NCT02431143 [137]), and paediatric post-kala-azar dermal leishmaniasis patients younger than 18 years old in Bangladesh (NCT02193022 [138]).

L-AMB pharmacokinetics have been characterised in paediatric patients in two population pharmacokinetic studies. Simulating different dosing regimens from 1 to $12.5 \mathrm{mg} / \mathrm{kg}$ daily for patients ranging $10-70 \mathrm{~kg}$ in weight, Hong et al. [92] reported that children under $20 \mathrm{~kg}$ would require a higher $\mathrm{mg} / \mathrm{kg}$ dose to achieve comparable steadystate $C_{\max }$ levels. However, weight could not be identified as a covariate on clearance in Japanese paediatric patients [93]. Lower serum AMB concentrations were also observed in children (17 days to 15 years old) receiving D-AMB [101], and body weight was found to be correlated with clearance and $V_{\mathrm{d}}[101,102]$.

One study reported on $\mathrm{Sb}$ pharmacokinetics in children. In treating both adults and children with $20 \mathrm{mg} \mathrm{Sb} / \mathrm{kg}$ daily, children reach only $58 \%$ of the $\mathrm{AUC}_{24}$ that adults reach [11]. Changing the dose in children to $30 \mathrm{mg} / \mathrm{kg}$ increased paediatric exposure to $86 \%$ of adult exposure after $20 \mathrm{mg} / \mathrm{kg}$. As expected, children have a higher weight-adjusted clearance $(0.185 \mathrm{~L} / \mathrm{h} / \mathrm{kg})$ than adults $(0.106 \mathrm{~L} / \mathrm{h} / \mathrm{kg})$, indicating that elimination does not change in direct proportion to weight.

In a large-scale paromomycin phase III trial in India (313 adults and 188 children aged 5-14 years old), no significant differences were found in paromomycin pharmacokinetics between adults and children [33, 38]. The $C_{\max }$ of children $(18.3 \pm 8.26 \mu \mathrm{g} / \mathrm{mL})$ was comparable to that of subjects older than 30 years $(19.1 \pm 9.75 \mu \mathrm{g} / \mathrm{mL})$ [38]. However, the same study reported weight to be a significant covariate on $V_{\mathrm{d}}$ and clearance. 
For pentamidine, concentration-time profiles were only available for two children ( 0.4 and 6 years old) and resembled the adult curves [57]. However, further investigation is required with a larger sample size to characterise pentamidine pharmacokinetics in paediatric patients.

\subsection{HIV-Visceral Leishmaniasis Co-Infected Patients}

In 2-9\% of VL cases, patients are co-infected with HIV, but this percentage rises to $40 \%$ in specific patient populations (reviewed in Alvar et al. [103]). Co-infection of HIV with VL results in rapid disease progression, more severe disease and a poor treatment response. Treatment options are limited in HIV-positive VL patients due to higher toxicity levels, generally low cure rates, high relapse rates and higher fatality than in immunocompetent patients [103].

As antiretroviral and antileishmanial drugs are thus often administered concurrently, possible drug-drug interactions could take place and should be evaluated. The pharmacokinetics of antiretroviral drugs have been reviewed previously [104]. Protease inhibitors are known inhibitors of CYP2D6 (only ritonavir) and CYP3A (all protease inhibitors) and their combination with pentamidine should therefore be monitored, as pentamidine has in vitro been found to be metabolised by these CYP enzymes. In addition, most non-nucleoside reverse transcriptase inhibitors (NNRTIs), such as nevirapine and efavirenz, are CYP3A enzyme inducers and combination with pentamidine could lead to suboptimal pentamidine exposure [105]. As other antileishmanial drugs are not metabolised by CYP enzymes, interactions on this level are not expected. The pharmacokinetics of pentamidine have been studied in AIDS patients, but their specific antiretroviral treatment was not reported [53, 54, 57]. It should be mentioned that protease inhibitors were not available at that time.

Vice versa, selective inhibition of CYP450 enzymes was observed in rats treated with D-AMB, assumed to be due to an impairment of monooxygenases on the endoplasmic reticulum [106]. This inhibitory effect on CYP450 activity was confirmed in humans [107]. This could increase exposure to NNRTIs, protease inhibitors and entry inhibitors as they are extensively metabolised by CYP450 enzymes. L-AMB did not affect CYP activity in rats [106].

Due to the high prevalence of nephrotoxicity on D-AMB treatment, drug-drug interactions should be expected with mostly renally cleared nucleoside reverse transcriptase inhibitors (NRTIs) such as lamivudine and emtricitabine. Concomitant use with other possibly nephrotoxic antiretrovirals, such as tenofovir, must also be closely monitored for renal function. Drug-drug interactions have not been evaluated in L-AMB and are expected to be much less pronounced due to the decreased nephrotoxicity. Extra caution is also required when combining the renally cleared $\mathrm{Sb}$ and paromomycin with antiretroviral drugs causing nephrotoxicity, such as tenofovir, as this could possibly affect antileishmanial drug exposure. Furthermore, as both pentamidine and nevirapine can be hepatotoxic, combination of these drugs should be monitored.

Miltefosine has in vitro been revealed to inhibit intestinal P-glycoprotein (P-gp) with short-term exposure. This suggests potential drug-drug interactions with substrates of intestinal P-gp [108], such as all protease inhibitors and the NRTI tenofovir alafenamide. In addition, as miltefosine has been found to widen tight junctions and promotes its own paracellular transport, other oral (hydrophilic) compounds relying on paracellular transport such as lamivudine and zidovudine might also be increasingly absorbed, influencing oral bioavailability [108].

Furthermore, for the antiretroviral drugs with high protein binding to albumin, such as efavirenz and raltegravir, competition for protein binding could take place with the highly protein-bound antileishmanial drugs pentamidine ( $\sim 70 \%)$, miltefosine (96-98\%) and AMB (>90\%). This could particularly be a problem in VL patients, who generally have severely lowered albumin levels $[109,110]$.

Pentamidine pharmacokinetics have been evaluated in AIDS patients but, due to the large heterogeneity of patients within studies and between studies, no conclusions can be drawn on potential differences with non-HIV patients. D-AMB pharmacokinetic parameters in five HIV patients [111] were in line with studies published for nonHIV patients $\left(C_{\max } 0.72 \mu \mathrm{g} / \mathrm{mL}\right.$ after $0.3 \mathrm{mg} / \mathrm{kg}$ dosing and $9.48 \mathrm{~mL} / \mathrm{h} / \mathrm{kg}$ clearance). The pharmacokinetics of other antileishmanial drugs have not been evaluated in HIV patients or HIV co-infected VL patients.

In addition, antiretroviral drug pharmacokinetics have not been evaluated in VL patients. VL causes a disruption of liver physiology, potentially affecting exposure of coinfected patients to NNRTIs and protease inhibitors given their metabolism by liver (CYP) enzymes.

Therefore, it is necessary to study the pharmacokinetics of these drugs in this difficult-to-treat patient population. One study has recently been performed investigating L-AMB in monotherapy and in combination therapy with miltefosine in HIV-VL co-infected patients in Ethiopia also receiving antiretroviral treatment (NCT02011958 [139]), but results have not been published yet.

\subsection{Pregnancy}

Treatment options for pregnant women are particularly limited in leishmaniasis patients. The use of pentavalent antimonials, pentamidine and miltefosine is 
contraindicated in pregnancy (FDA categories C, C and D, respectively), and thus the only treatment options are paromomycin (no category assigned) and AMB (FDA category B) (reviewed in Fontenele e Silva et al. [112]). The physiological changes in pregnant women are known to possibly alter the ADME of drugs and could thus potentially affect the exposure to drugs. Furthermore, long $t_{1 / 2}$ values of antileishmanial drugs might also require the use of contraceptives in women of reproductive age.

$\mathrm{Sb}$ has been correlated with adverse pregnancy outcomes (such as abortions, preterm births and stillbirths) [113-115]. Evidence for the mutagenic, carcinogenic and teratogenic effect of $\mathrm{Sb}$ is still scarce, but should probably be assumed [116]. Placental transfer of Sb was established in rats and $\mathrm{Sb}$ was transferred to pups via milk $[117,118]$. At a daily dose of $300 \mathrm{mg} \mathrm{Sb} / \mathrm{kg}$, fetal growth retardation and increased embryo lethality and skeleton anomalies were observed [117, 119].

An obstacle to the widespread use of miltefosine in the clinic is its potential reproductive toxicity, reported as a result of pre-clinical in vivo studies in rats and rabbits [64]. Treatment of rats with miltefosine $1-2 \mathrm{mg} / \mathrm{kg}$ in early embryonic development and organogenesis resulted in embryotoxic, fetotoxic and teratogenic risk, indicating placental transfer [64]. While pentamidine in theory could hold teratogenic properties due to its inhibition of protein and nucleic acid synthesis in vitro, rat studies found a feticidal but not teratogenic effect in doses similar to human recommended dosages [120].

Both miltefosine and pentamidine have long terminal $t_{1 / 2}$ values. Miltefosine concentrations are still detectable in plasma up to 6 months after the end of treatment [70], and could thus still be harmful during pregnancy for long periods after end of treatment. A translational pharmacokinetic study advised that the duration of contraceptive use after treatment be 4 months after a 28 -day miltefosine treatment, with a $<0.1 \%$ probability of exceeding the NOAEL (no-observed-adverse-effect level) [121]. Pentamidine also has a relatively long terminal $t_{1 / 2}$ of $\sim 12$ days, which could have implications for the contraceptive duration required; however, this has not been studied.

Both paromomycin and AMB are not contraindicated in treatment of leishmaniasis patients. However, no studies have been performed on the pharmacokinetics of both antileishmanial drugs in pregnant or breastfeeding women. Animal studies (rat and rabbit) show that paromomycin is not teratogenic [32]. There are some worries about possible ototoxicity in the unborn child, as the aminoglycoside streptomycin has been reported to have possibly caused cases of ototoxicity in the unborn child when administered to women during pregnancy [122]. No studies have been performed on the excretion of paromomycin into breast milk; however, due to its poor lipid solubility and limited distribution, substantial excretion in breast milk is not expected. AMB has been found to cross the placenta in cord blood:maternal serum ratios between 0.38 and 1.51 (reviewed in Pilmis et al. [123]). Rodent and rabbit studies showed no teratogenicity at ten times the recommended human dose (reviewed in Pilmis et al. [123]).

\subsection{Patients with Renal Impairment}

The main route of elimination of both $\mathrm{Sb}$ and paromomycin is renal clearance, and they can thus be expected to be drastically impacted by renal impairment. Only a single report describes $\mathrm{Sb}$ pharmacokinetics in a VL patient with acute renal failure (glomerular filtration rate of $16 \mathrm{~mL} / \mathrm{min}$ ). After treatment with $25 \mathrm{mg} \mathrm{MA} / \mathrm{kg}$ daily, $C_{\max }$ was elevated $(22.9 \mu \mathrm{g} / \mathrm{mL}), C_{\text {trough }}$ was particularly high at $9.3 \mu \mathrm{g} / \mathrm{mL}$ and the $t_{1 / 2}$ was more than seven times higher $(15 \mathrm{~h})$ than in patients with normal renal function. The paromomycin $t_{1 / 2}$ was increased from $2.47 \mathrm{~h}$ for normal subjects to $6.7 \mathrm{~h}$ for patients with a creatinine clearance of 30-60 $\mathrm{mL} / \mathrm{min}$ and was as high as $36.6 \mathrm{~h}$ for patients with a creatinine clearance of less than $10 \mathrm{~mL} / \mathrm{min}$ [124]. In treating patients with renal impairment, $\mathrm{Sb}$ and paromomycin dose reductions are therefore advised.

For D-AMB, $\sim 20 \%$ of the administered dose is renally excreted within 1 week. No pharmacokinetic parameters have been defined for patients with renal impairment, but a dose of D-AMB $1 \mathrm{mg} / \mathrm{kg}$ was well-tolerated in a VL patient on haemodialysis [125]. No AMB could be identified in peritoneal dialysate [126], as expected due to high AMB protein binding.

For pentamidine, miltefosine and L-AMB, no effect of renal impairment on pharmacokinetic parameters is expected, as only a small percentage is cleared by the kidneys (pentamidine/L-AMB $<5 \%$ [53, 54, 57, 87], miltefosine $<0.2 \%$ [61]). Pentamidine pharmacokinetic parameters were indeed not significantly different in patients with impaired renal function, receiving haemodialysis or peritoneal dialysis compared with patients with normal renal function [54, 57]. No results have been published on miltefosine pharmacokinetics in patients with renal impairment, but haemodialysis did not affect steady-state miltefosine concentrations in two patients with terminal renal failure (Kip and Dorlo, unpublished data). After L-AMB administration, the AMB concentration-time profiles were also not affected by haemodialysis or haemofiltration [95, 127], implying that AMB does not pass through extracorporal filtration membranes. In contrast, another study found a higher total AMB clearance in critically ill patients receiving continuous veno-venous hemofiltration $(0.14 \mathrm{~L} / \mathrm{h} / \mathrm{kg})$ than in patients 
that do not $(0.061 \mathrm{~L} / \mathrm{h} / \mathrm{kg})$, though no significant differences in $C_{\max }$ and $\mathrm{AUC}_{24}$ were observed [128].

\section{Drug-Drug Interactions Between Antileishmanial Drugs}

In specific patient populations and certain regions, the antileishmanial drugs currently available are not sufficient due to lack of efficacy, increasing drug resistance, parenteral administration or severe adverse effects. Combining several antileishmanial drugs could possibly solve these issues and improve the therapeutic outcome in leishmaniasis treatment. In addition, it could shorten treatment duration. In the clinical studies on combination therapies performed to date, no clinical pharmacokinetic evaluations of drug-drug interactions have been performed, but pharmacokinetic interactions could potentially affect the safety of and exposure to the independent drugs.

Caution is required in the combination of D-AMB with paromomycin or pentamidine due to the possibility of cumulative risk of nephrotoxicity. In addition, the metabolism of pentamidine could potentially be affected due to CYP inhibition by D-AMB [106]. Furthermore, as both Sb and paromomycin are renally excreted, their combination with nephrotoxic antileishmanials (especially D-AMB) should be monitored.

As described previously, miltefosine was found to be an intestinal P-gp inhibitor and AMB was reported to be a substrate for P-gp [129], although this has been contested [130]. As both miltefosine and AMB are amphiphilic molecules, AMB monomers were found to be incorporated in micellar formations of miltefosine if miltefosine is present at levels above its critical micelle concentration [131]. This could alter the drug distribution of both AMB and miltefosine. Further information on the pharmacokinetics of combined administration of miltefosine and AMB will arise from a clinical study currently being conducted in Ethiopia (NCT02011958 [139]).

\section{Directions for Future Advancements in Clinical Pharmacokinetic Research in Leishmaniasis}

To date, clinical pharmacokinetic studies have only been performed in leishmaniasis patients for $\mathrm{Sb}$, paromomycin and miltefosine. Performing these studies also for pentamidine and AMB is crucial in rationalising treatment design, as VL could potentially affect the pharmacokinetics of pentamidine and AMB due to alterations in hepatic physiology and clinical conditions such as hypoalbuminaemia.

For the drugs systemically administered in treatment of $\mathrm{CL}$, limited information is available on the distribution of the drug towards the skin or skin lesions, which forms the target site of action. In addition, only one study evaluated intracellular drug concentrations. As the Leishmania parasite resides within macrophages, and most antileishmanial drugs exert their action intracellularly, future research should elaborate on intracellular drug exposure. Especially for $\mathrm{Sb}^{\mathrm{V}}$, which is converted into the active $\mathrm{Sb}^{\mathrm{III}}$ intracellularly, these concentrations probably more accurately reflect the effective drug concentration to which the parasite is exposed. Information on the intracellular drug pharmacokinetics could be particularly useful to establish exposure-response relationships.

Furthermore, exposure-response studies linking the pharmacokinetics of antileishmanial drugs to treatment outcome have only been performed for miltefosine to date [72] (Dorlo et al., unpublished data). These studies are essential in the rationalisation of the dose, the schedule of antileishmanial treatment and the combination of different antileishmanial drugs. In addition, defining exposure-response relationships is especially important in investigating the possible pharmacokinetic basis for drug resistance.

More research is required in optimising dosing regimens for paediatric patients. Though efforts have been made to specifically evaluate different dosing regimens in paediatric leishmaniasis patients, special dosing regimens are currently only being clinically evaluated for miltefosine, while an adjusted dosage has also been proposed for L-AMB [92].

Population pharmacokinetic modelling could be a valuable tool in future pharmacokinetic research, especially in drugs with large variability in exposure, such as L-AMB. Population pharmacokinetic modelling also provides the opportunity to evaluate the allometric scaling of body size on clearance and $V_{\mathrm{d}}$. Furthermore, full pharmacokinetic analysis can be performed with relatively limited sampling. Sparse sampling is particularly convenient in pharmacokinetic studies of antileishmanial drugs, as approximately half of the population is paediatric, requiring less intensive sampling schemes. Furthermore, clinical trials are often conducted in remote settings, making sampling and follow-up difficult, and consistent timing of sampling required for non-compartmental analysis is therefore challenging. For these sparse and heterogeneously collected pharmacokinetic samples, population pharmacokinetic modelling is especially valuable.

Regarding pharmacokinetic sampling, there is room for improvement by employing newer collection techniques such as the less invasive dried blood spot sampling [132]. Dried blood spot samples can be stored and shipped at room temperature, simplifying pharmacokinetic sampling, enabling easier sample transport logistics, and reducing costs, which is particularly valuable in remote and resource-poor VL and CL areas of endemicity. 


\section{Compliance with Ethical Standards}

Funding Thomas P.C. Dorlo was supported by the Netherlands Organisation for Scientific Research (NWO) through a personal Veni grant (Project Number 91617140).

Conflict of interest Anke E. Kip, Jan H.M. Schellens, Jos H. Beijnen and Thomas P.C. Dorlo have no conflicts of interest that are relevant to the content of this review.

Open Access This article is distributed under the terms of the Creative Commons Attribution-NonCommercial 4.0 International License (http://creativecommons.org/licenses/by-nc/4.0/), which permits any noncommercial use, distribution, and reproduction in any medium, provided you give appropriate credit to the original author(s) and the source, provide a link to the Creative Commons license, and indicate if changes were made.

\section{References}

1. Copeland NK, Aronson NE. Leishmaniasis: treatment updates and clinical practice guidelines review. Curr Opin Infect Dis. 2015;28:426-37.

2. WHO. Control of the leishmaniases. WHO Technical Report Series \#949. 2010. http://apps.who.int/iris/bitstream/10665/ 44412/1/WHO_TRS_949_eng.pdf. Accessed 7 Feb 2017.

3. Croft SL, Olliaro P. Leishmaniasis chemotherapy—challenges and opportunities. Clin Microbiol Infect. 2011;17:1478-83.

4. Sundar S, Singh A. Recent developments and future prospects in the treatment of visceral leishmaniasis. Ther Adv Infect Dis. 2016;3:98-109.

5. Monge-Maillo B, López-Vélez R. Miltefosine for visceral and cutaneous leishmaniasis: drug characteristics and evidence-based treatment recommendations. Clin Infect Dis. 2015;60:1398-404.

6. Verrest L, Dorlo TPC. Lack of clinical pharmacokinetic studies to optimize the treatment of neglected tropical diseases: a systematic review. Clin Pharmacokinet. 2017;56(6):583-606.

7. Dorlo TPC, Balasegaram M, Beijnen JH, de Vries PJ. Miltefosine: a review of its pharmacology and therapeutic efficacy in the treatment of leishmaniasis. J Antimicrob Chemother. 2012;67:2576-97.

8. Stone NRH, Bicanic T, Salim R, Hope W. Liposomal amphotericin B (AmBisome ${ }^{\circledR}$ ): a review of the pharmacokinetics, pharmacodynamics, clinical experience and future directions. Drugs. 2016;76:485-500.

9. US Food and Drug Administration FDA. FDA limits usage of Nizoral (ketoconazole) oral tablets due to potentially fatal liver injury and risk of drug interactions and adrenal gland problems. 2013. http://www.fda.gov/downloads/drugs/drugsafety/ucm 362 444.pdf. Accessed 7 Feb 2017.

10. Vásquez L, Scorza Dagert JV, Scorza JV, Vicuna-Fernández N, de Pena YP, López S, et al. Pharmacokinetics of experimental pentavalent antimony after intramuscular administration in adult volunteers. Curr Ther Res. 2006;67:193-203.

11. Cruz A, Rainey PM, Herwaldt BL, Stagni G, Palacios R, Trujillo $\mathrm{R}$, et al. Pharmacokinetics of antimony in children treated for leishmaniasis with meglumine antimoniate. J Infect Dis. 2007:195:602-8.

12. Frézard F, Demicheli C, Ribeiro RR. Pentavalent antimonials: new perspectives for old drugs. Molecules. 2009;14:2317-36.

13. Baiocco P, Colotti G, Franceschini S, Ilari A. Molecular basis of antimony treatment in leishmaniasis. $\mathrm{J}$ Med Chem. 2009;52:2603-12.
14. Mookerjee Basu J, Mookerjee A, Sen P, Bhaumik S, Sen P, Banerjee $S$, et al. Sodium antimony gluconate induces generation of reactive oxygen species and nitric oxide via phosphoinositide 3-kinase and mitogen-activated protein kinase activation in Leishmania donovani-infected macrophages. Antimicrob Agents Chemother. 2006;50:1788-97.

15. Mookerjee Basu J, Mookerjee A, Banerjee R, Saha M, Singh S, Naskar K, et al. Inhibition of ABC transporters abolishes antimony resistance in Leishmania infection. Antimicrob Agents Chemother. 2008;52:1080-93.

16. Oliveira LF, Schubach AO, Martins MM, Passos SL, Oliveira $\mathrm{RV}$, Marzochi MC, et al. Systematic review of the adverse effects of cutaneous leishmaniasis treatment in the New World. Acta Trop. 2011;118:87-96.

17. Sundar S, Chakravarty J. Antimony toxicity. Int J Environ Res Public Health. 2010;7:4267-77.

18. Chulay JD, Fleckenstein L, Smith DH. Pharmacokinetics of antimony during treatment of visceral leishmaniasis with sodium stibogluconate or meglumine antimoniate. Trans R Soc Trop Med Hyg. 1988;82:69-72.

19. Zaghloul IY, Radwan MA, Al Jaser MH, Al Issa R. Clinical efficacy and pharmacokinetics of antimony in cutaneous leishmaniasis patients treated with sodium stibogluconate. J Clin Pharmacol. 2010;50:1230-7.

20. Al Jaser M, El-Yazigi A, Kojan M, Croft SL. Skin uptake, distribution, and elimination of antimony following administration of sodium stibogluconate to patients with cutaneous leishmaniasis. Antimicrob Agents Chemother. 1995;39:516-9.

21. Abdallah A, Saif M. Trace studies with antimony 124 in man. In: Wolstenholme GEW, O'Connor M, editors. Bilharziasis. London: Churchill; 1962. p. 287-309.

22. Friedrich K, Vieira FA, Porrozzi R, Marchevsky RS, Miekeley $\mathrm{N}$, Grimaldi G, et al. Disposition of antimony in rhesus monkeys infected with Leishmania braziliensis and treated with meglumine antimoniate. J Toxicol Environ Health A. 2012;75:63-75.

23. Coelho DR, Miranda ES, Saint'Pierre TD, Roma Paumgartten FJ. Tissue distribution of residual antimony in rats treated with multiple doses of meglumine antimoniate. Mem Inst Oswaldo Cruz. 2014;109:420-7.

24. Dorea JG, Merchan-Hamann E, Ryan DE, Holzbecher J. Retention of antimony in skin biopsies of Leishmaniasis patients after treatment with $\mathrm{N}$-methylglucamine antimoniate. Clin Chem. 1990;36:680-2.

25. Da Justa Neves DB, Caldas ED, Sampaio RNR. Antimony in plasma and skin of patients with cutaneous leishmaniasis-relationship with side effects after treatment with meglumine antimoniate. Trop Med Int Health. 2009;14:1515-22.

26. Miekeley N, Mortari SR, Schubach AO. Monitoring of total antimony and its species by ICP-MS and on-line ion chromatography in biological samples from patients treated for leishmaniasis. Anal Bioanal Chem. 2002;372:495-502.

27. Dos Santos Ferreira C, Silveira Martins P, Demicheli C, Brochu C, Ouellette M, Frézard F. Thiol-induced reduction of antimony(V) into antimony(III): a comparative study with trypanothione, cysteinyl-glycine, cysteine and glutathione. BioMetals. 2003; 16:441-6.

28. Rees PH, Keating MI, Kager PA, Hockmeter WT. Renal clearance of pentavalent antimony (sodium stibogluconate). Lancet. 1980;2:226-9.

29. Pamplin CL, Desjardins R, Chulay J, Tramont E, Hendricks L, Canfield C. Pharmacokinetics of antimony during sodium stibogluconate therapy for cutaneous leishmaniasis. Clin Pharmacol Ther. 1981;29:270-1.

30. Al-Jaser M, El-Yazigi A, Croft SL. Pharmacokinetics of antimony in patients treated with sodium stibogluconate for cutaneous leishmaniasis. Pharm Res. 1995;12:111-4. 
31. Davidson RN, den Boer M, Ritmeijer K. Paromomycin. Trans R Soc Trop Med Hyg. 2009;103:653-60.

32. Institute for One World Health. Application for inclusion of paromomycin in the WHO Model List of Essential Medicines. 2006. http://archives.who.int/eml/expcom/expcom15/applications/ newmed/paromomycin/paromomycin.pdf. Accessed 7 Feb 2017.

33. Sundar S, Jha TK, Thakur CP, Sinha PK, Bhattacharya SK. Injectable paromomycin for visceral leishmaniasis in India. N Engl J Med. 2007;356:2571-81.

34. Hens B, Brouwers J, Anneveld B, Corsetti M, Symillides M, Vertzoni M, et al. Gastrointestinal transfer: In vivo evaluation and implementation in in vitro and in silico predictive tools. Eur J Pharm Sci. 2014;63:233-42.

35. Bissuel F, Cotte L, de Montclos M, Rabodonirina M, Trepo C. Absence of systemic absorption of oral paromomycin during long-term, high-dose treatment for cryptosporidiosis in AIDS. J Infect Dis. 1994;170:749-50.

36. Kanyok TP, Killian AD, Rodvold KA, Danziger LH. Pharmacokinetics of intramuscularly administered aminosidine in healthy subjects. Antimicrob Agents Chemother. 1997;41:982-6.

37. Musa AM, Younis B, Fadlalla A, Royce C, Balasegaram M, Wasunna M, et al. Paromomycin for the treatment of visceral leishmaniasis in Sudan: a randomized, open-label, dose-finding study. PLoS Negl Trop Dis. 2010;4:4-10.

38. Kshirsagar S, Mordenti J, Blaschke T. Clinical pharmacokinetics of paromomycin sulfate in Indian visceral leishmaniasis patients [poster no. A-1105]. In: 46th Interscience conference on antimicrobial agents and chemotherapy (ICAAC); 27-30 September 2006; San Francisco, CA. Washington, DC: ASM Press; 2006.

39. Belloli C, Crescenzo G, Carli S, Villa R, Sonzogni O, Carelli G, et al. Pharmacokinetics and dosing regimen of aminosidine in the dog. Vet Res Commun. 1996;20:533-41.

40. Gordon RC, Regamey C, Kirby WMM. Serum protein binding of the aminoglycoside antibiotics. Antimicrob Agents Chemother. 1972;2:214-6.

41. Paromomycin Seyffart G. In: Seyffart G, editor. Drug dosing in renal insufficiency. Dordrecht: Spinger; 1991. p. 448.

42. Kirby WMM, Clarke JT, Libke RD, Regamey C. Clinical pharmacology of amikacin and kanamycin. J Infect Dis. 1976;134:S312-5.

43. Mudawi MME, Khalil EAG, Eltayeb IB, Musa AM, Shaddad SAI, Githiga IM, et al. The pharmacokinetics of paromomycin (aminosidine) in healthy volunteers and kala-azar patients. In: Annual conference of graduate studies and scientific research, medical and health studies, University of Khartoum; 2011; Khartoum.

44. Maarouf M, Adeline M, Solignac M, Vautrin D, Robert-Gero M. Development and characterization of paromomycin-resistant Leishmania donovani promastigotes. Parasite. 1998;5:167-73.

45. Coelho AC, Messier N, Ouellette M, Cotrim PC. Role of the $\mathrm{ABC}$ transporter PRP1 (ABCC7) in pentamidine resistance in Leishmania amastigotes. Antimicrob Agents Chemother. 2007;51:3030-2.

46. Kotthaus J, Kotthaus J, Schade D, Schwering U. New prodrugs of the antiprotozoal drug pentamidine. ChemMedChem. 2011;6:2233-42.

47. Bronner U, Doua F, Ericsson Ö, Gustafsson LL, Miézan TW, Rais $M$, et al. Pentamidine concentrations in plasma, whole blood and cerebrospinal fluid during treatment of Trypanosoma gambiense infection in Côte d'Ivoire. Trans R Soc Trop Med Hyg. 1991;85:608-11.

48. Donnelly H, Bernard EM, Rothkotter H, Gold JWM, Armstrong D. Distribution of pentamidine in patients with AIDS. J Infect Dis. 1988;157:985-9.
49. Thomas SHL, Page CJ, Blower PJ, Chowienczyk P, Ward A, Kamali F, et al. Disposition of intravenous 123-iodopentamidine in man. Nucl Med Biol. 1997;24:327-32.

50. Berger BJ, Naiman NA, Hall JE, Peggins J, Brewer TG, Tidwell RR. Primary and secondary metabolism of pentamidine by rats. Antimicrob Agents Chemother. 1992;36:1825-31.

51. Bronner U, Gustafsson LL, Doua F, Ericsson Ö, Miézan T, Rais $\mathrm{M}$, et al. Pharmacokinetics and adverse reactions after a single dose of pentamidine in patients with Trypanosoma gambiense sleeping sickness. Br J Clin Pharmacol. 1995;39:289-95.

52. Li X, Björkman A, Andersson TB, Gustafsson LL, Masimirembwa CM. Identification of human cytochrome P450s that metabolise anti-parasitic drugs and predictions of in vivo drug hepatic clearance from in vitro data. Eur J Clin Pharmacol. 2003;59:429-42.

53. Conte JE Jr, Upton RA, Phelps RT, Wofsy CB, Zurlinden E, Lin ET. Use of a specific and sensitive assay to determine pentamidine pharmacokinetics in patients with AIDS. J Infect Dis. 1986;154:923-9.

54. Conte JE Jr. Pharmacokinetics of intravenous pentamidine in patients with normal renal function or receiving hemodialysis. J Infect Dis. 1991;163:169-75.

55. Waalkes TP, Denham C, DeVita VT. Pentamidine: clinical pharmacologic correlations in man and mice. Clin Pharmacol Ther. 1970;11:505-12.

56. Vöhringer HF, Arasteh K, Link H, Ehninger G, Hardtmann I. Determinants of serum pentamidine concentration in the human (in German). Med Klin (Munich). 1992;87:24-9.

57. Conte JE Jr, Upton RA, Lin ET. Pentamidine pharmacokinetics in patients with AIDS with impaired renal function. J Infect Dis. 1987;156:885-90.

58. Comtois R, Pouliot J, Vinet B, Gervais A, Lemieux C. Higher pentamidine levels in AIDS patients with hypoglycemia and azotemia during treatment of pneumocystis carinii pneumonia. Am Rev Respir Dis. 1992;146:740-4.

59. Samanta TB, Das N, Das M, Marik R. Mechanism of impairment of cytochrome P450-dependent metabolism in hamster liver during leishmaniasis. Biochem Biophys Res Commun. 2003;312:75-9.

60. Barioni MB, Ramos AP, Zaniquelli MED, Acuña AU, Ito AS. Miltefosine and BODIPY-labeled alkylphosphocholine with leishmanicidal activity: aggregation properties and interaction with model membranes. Biophys Chem. 2015;196:92-9.

61. Berman J. Miltefosine to treat leishmaniasis. Expert Opin Pharmacother. 2005;6:1381-8.

62. Kötting J, Marschner NW, Neumüller W, Unger C, Eibl H. Hexadecylphosphocholine and octadecyl-methyl-glycero-3phosphocholine: a comparison of hemolytic activity, serum binding and tissue distribution. Prog Exp Tumor Res. 1992;34:131-42.

63. Moreira RA, Mendanha SA, Hansen D, Alonso A. Interaction of miltefosine with the lipid and protein components of the erythrocyte membrane. J Pharm Sci. 2013;102:1661-9.

64. Sindermann H, Engel J. Development of miltefosine as an oral treatment for leishmaniasis. Trans R Soc Trop Med Hyg. 2006;100:2-5.

65. Marschner N, Kötting J, Eibl H, Unger C. Distribution of hexadecylphosphocholine and octadecyl-methyl-glycero-3-phosphocholine in rat tissues during steady-state treatment. Cancer Chemother Pharmacol. 1992;31:18-22.

66. Breiser A, Kim DJ, Fleer EA, Damenz W, Drube A, Berger M, et al. Distribution and metabolism of hexadecylphosphocholine in mice. Lipids. 1987;22:925-6.

67. Kip AE, Rosing H, Hillebrand MJX, Castro MM, Gomez MA, Schellens JHM, et al. Quantification of miltefosine in peripheral blood mononuclear cells by high-performance liquid 
chromatography-tandem mass spectrometry. J Chromatogr B Anal Technol Biomed Life Sci. 2015;6:356-72.

68. Roy SL, Atkins JT, Gennuso R, Kofos D, Sriram RR, Dorlo TPC, et al. Assessment of blood-brain barrier penetration of miltefosine used to treat a fatal case of granulomatous amebic encephalitis possibly caused by an unusual Balamuthia mandrillaris strain. Parasitol Res. 2015;114:4431-9.

69. Bianciardi P, Brovida C, Valente M, Aresu L, Cavicchioli L, Vischer C, et al. Administration of miltefosine and meglumine antimoniate in healthy dogs: clinicopathological evaluation of the impact on the kidneys. Toxicol Pathol. 2009;37:770-5.

70. Dorlo TPC, Van Thiel PPAM, Huitema ADR, Keizer RJ, De Vries HJC, Beijnen JH, et al. Pharmacokinetics of miltefosine in old world cutaneous leishmaniasis patients. Antimicrob Agents Chemother. 2008;52:2855-60.

71. Dorlo TPC, Huitema ADR, Beijnen JH, De Vries PJ. Optimal dosing of miltefosine in children and adults with visceral leishmaniasis. Antimicrob Agents Chemother. 2012;56:3864-72.

72. Dorlo TPC, Rijal S, Ostyn B, De Vries PJ, Singh R, Bhattarai N, et al. Failure of miltefosine in visceral leishmaniasis is associated with low drug exposure. J Infect Dis. 2014;210:146-53.

73. Welte R, Eschertzhuber S, Weiler S, Leitner-Rupprich S, Aigner $\mathrm{M}$, Lass-Florl C, et al. Biliary amphotericin B pharmacokinetics and pharmacodynamics in critically ill liver transplant recipients receiving treatment with amphotericin B lipid formulations. Int $\mathbf{J}$ Antimicrob Agents. 2015;46:325-31.

74. Janknegt R, de Marie S, Bakker-Woudenberg IAJM, Crommelin DJA. Liposomal and lipid formulations of amphotericin B: clinical pharmacokinetics. Clin Pharmacokinet. 1992;23:279-91.

75. Block ER, Bennett JE, Livoti LG, Klein WJJ, MacGregor RR, Henderson L. Flucytosine and amphotericin B: hemodialysis effects on the plasma concentration and clearance: studies in man. Ann Intern Med. 1974;80:613-7.

76. Bekersky I, Fielding RM, Dressler DE, Lee JW, Buell DN, Walsh TJ. Plasma protein binding of amphotericin B and pharmacokinetics of bound versus unbound amphotericin B after administration of intravenous liposomal amphotericin B (AmBisome) and amphotericin B deoxycholate. Antimicrob Agents Chemother. 2002;46:834-40.

77. Kagan L, Gershkovich P, Wasan KM, Mager DE. Dual physiologically based pharmacokinetic model of liposomal and nonliposomal amphotericin B disposition. Pharm Res. 2014;31:35-45.

78. Ringdén O, Meunier F, Tollemar J, Ricci P, Tura S, Kuse E, et al. Efficacy of amphotericin B encapsulated in liposomes (AmBisome) in the treatment of invasive fungal infections in immunocompromised patients. J Antimicrob Chemother. 1991;28:73-82.

79. Vogelsinger H, Weiler S, Djanani A, Kountchev J, BellmannWeiler R, Wiedermann CJ, et al. Amphotericin B tissue distribution in autopsy material after treatment with liposomal amphotericin B and amphotericin B colloidal dispersion. J Antimicrob Chemother. 2006;57:1153-60.

80. Strenger V, Meinitzer A, Donnerer J, Hofer N, Dornbusch HJ, Wanz U, et al. Amphotericin B transfer to CSF following intravenous administration of liposomal amphotericin B. J Antimicrob Chemother. 2014;69:2522-6.

81. Christiansen KJ, Bernard EM, Gold JWM, Armstrong D. Distribution and activity of amphotericin B in humans. J Infect Dis. 1985;152:1037-43.

82. Smith PJ, Olson JA, Constable D, Schwartz J, Proffitt RT, Adler-Moore JP. Effects of dosing regimen on accumulation, retention and prophylactic efficacy of liposomal amphotericin B. J Antimicrob Chemother. 2007;59:941-51.

83. Boswell GW, Buell D, Bekersky I. Am Bisome (liposomal amphotericin B): a comparative review. J Clin. 1998;38:583-92.
84. Gershkovich P, Wasan EK, Sivak O, Li R, Zhu X, Werbovetz $\mathrm{KA}$, et al. Visceral leishmaniasis affects liver and spleen concentrations of amphotericin B following administration to mice. J Antimicrob Chemother. 2009;65:535-7.

85. Fielding RM, Smith PC, Wang LH, Porter J, Guo LSS. Comparative pharmacokinetics of amphotericin B after administration of a novel colloidal delivery system, $\mathrm{ABCD}$, and a conventional formulation to rats. Antimicrob Agents Chemother. 1991;35:1208-13.

86. Gubbins PO, Amsden JR, McConnell SA, Anaissie EJ. Pharmacokinetics and buccal mucosal concentrations of a 15 milligram per kilogram of body weight total dose of liposomal amphotericin B administered as a single dose $(15 \mathrm{mg} / \mathrm{kg})$, weekly dose $(7.5 \mathrm{mg} / \mathrm{kg})$, or daily dose $(1 \mathrm{mg} / \mathrm{kg})$ in peripheral stem cell tran. Antimicrob Agents Chemother. 2009;53:3664-74.

87. Bekersky I, Fielding RM, Dressler DE, Lee W, Buell DN, Walsh TJ, et al. Pharmacokinetics, excretion, and mass balance of liposomal amphotericin B (AmBisome) and amphotericin B deoxycholate in humans. Antimicrob Agents Chemother. 2002;46:828-33.

88. Walsh TJ, Goodman JL, Pappas P, Bekersky I, Buell DN, Roden $\mathrm{M}$, et al. Safety, tolerance and pharmacokinetics of high-dose liposomal amphotericin B (AmBisome) in patients infected with Aspergillus species and other filamentous fungi: maximum tolerated dose study. Antimicrob Agents Chemother. 2001;45:3487-96.

89. Walsh TJ, Yeldandi V, McEvoy M, Gonzalez C, Chanock S, Freifeld A, et al. Safety, tolerance, and pharmacokinetics of a small unilamellar liposomal formulation of amphotericin B (AmBisome) in neutropenic patients. Antimicrob Agents Chemother. 1998;42:2391-8.

90. Hope WW, Goodwin J, Felton TW, Ellis M, Stevens DA. Population pharmacokinetics of conventional and intermittent dosing of liposomal amphotericin B in adults: a first critical step for rational design of innovative regimens. Antimicrob Agents Chemother. 2012;56:5303-8.

91. Würthwein G, Young C, Lanvers-Kaminsky C, Hempel G, Trame MN, Schwerdtfeger R, et al. Population pharmacokinetics of liposomal amphotericin B and caspofungin in allogeneic hematopoietic stem cell recipients. Antimicrob Agents Chemother. 2012;56:536-43.

92. Hong Y, Nath CE, Yadav SP, Stephen KR, Earl JW, Mclachlan AJ. Population pharmacokinetics of liposomal amphotericin B in pediatric patients with malignant diseases. Antimicrob Agents Chemother. 2006;50:935-42.

93. Ohata Y, Tomita Y, Suzuki K, Maniwa T, Yano Y, Sunakawa K. Pharmacokinetic evaluation of liposomal amphotericin B (LAMB) in patients with invasive fungal infection: population approach in Japanese pediatrics. Drug Metab Pharmacokinet. 2015;30:400-9.

94. Lestner JM, Groll AH, Aljayyoussi G, Seibel NL, Shad A, Gonzalez C, et al. Population pharmacokinetics of liposomal amphotericin B in immunocompromised children. Antimicrob Agents Chemother. 2016;60:7340-6.

95. Heinemann V, Bosse D, Jehn U, Kahny B, Wachholz K, Debus A, et al. Pharmacokinetics of liposomal amphotericin B (Ambisome) in critically ill patients. Antimicrob Agents Chemother. 1997;41:1275-80.

96. Institute for Health Metrics and Evaluation (IHME). GBD Results Tool. Seattle: IHME, University of Washington, 2016. http://ghdx.healthdata.org/gbd-results-tool. Accessed 7 Feb 2017.

97. Anderson BJ, Holford NHG. Mechanism-based concepts of size and maturity in pharmacokinetics. Annu Rev Pharmacol Toxicol. 2008;48:303-32. 
98. Ostyn B, Hasker E, Dorlo TPC, Rijal S, Sundar S, Dujardin J, et al. Failure of miltefosine treatment for visceral leishmaniasis in children and men in South-East Asia. PLoS One. 2014;9:e100220.

99. Rijal S, Ostyn B, Uranw S, Rai K, Bhattarai NR, Dorlo TPC, et al. Increasing failure of miltefosine in the treatment of kalaazar in Nepal and the potential role of parasite drug resistance, reinfection, or noncompliance. Clin Infect Dis. 2013;56:1530-8.

100. Castro MM, Gomez MA, Kip AE, Cossio A, Ortiz E, Navas A, et al. Pharmacokinetics of miltefosine in children and adults with cutaneous leishmaniasis. Antimicrob Agents Chemother. 2017;61(3):e02198-16.

101. Starke JR, Mason EO Jr, Kramer WG, Sheldon L, Starke JR, Mason EO, et al. Pharmacokinetics of amphotericin B in infants and children. J Infect Dis. 1987;155:766-74.

102. Koren G, Lau A, Klein J, Golas C, Bologa-Campeanu M, Soldin $\mathrm{S}$, et al. Pharmacokinetics and adverse effects of amphotericin B in infants and children. J Pediatr. 1988;113:559-63.

103. Alvar J, Aparicio P, Aseffa A, Den Boer M, Cañavate C, Dedet JP, et al. The relationship between leishmaniasis and AIDS: the second 10 years. Clin Microbiol Rev. 2008;21:334-59.

104. Tittle V, Bull L, Boffito M, Nwokolo N. Pharmacokinetic and pharmacodynamic drug interactions between antiretrovirals and oral contraceptives. Clin Pharmacokinet. 2015;54:23-34.

105. Fellay J, Marzolini C, Decosterd L, Golay KP, Baumann P, Buclin $\mathrm{T}$, et al. Variations of CYP3A activity induced by antiretroviral treatment in HIV-1 infected patients. Eur J Clin Pharmacol. 2005;60:865-73.

106. Inselmann G, Volkmann A, Heidemann HT. Comparison of the effects of liposomal amphotericin B and conventional amphotericin $\mathrm{B}$ on propafenone metabolism and hepatic cytochrome P-450 in rats. Antimicrob Agents Chemother. 2000;44:131-3.

107. Brockmeyer NH, Gambichler T, Bader A, Kreuter A, Kurowski M, Sander P, et al. Impact of Amphotericin B on the cytochrome P450 system in HIV-infected patients. Eur $\mathrm{J}$ Med Res. 2006;9:51-4.

108. Menez C, Buyse M, Chacun H, Farinotti R, Barratt G. Modulation of intestinal barrier properties by miltefosine. Biochem Pharmacol. 2006;71:486-96.

109. Brustoloni YM, Cunha RV, Cônsolo LZ, Oliveira ALL, Dorval MEC, Oshiro ET. Treatment of visceral leishmaniasis in children in the Central-West Region of Brazil. Infection. 2010;38:261-7.

110. Libório AB, Rocha NA, Oliveira MJC, Franco LFLG, Aguiar GBR, Pimentel RS, et al. Acute kidney injury in children with visceral leishmaniasis. Pediatr Infect Dis J. 2012;31:451-4.

111. Adedoyin A, Bernardo JF, Swenson CE, Bolsack LE, Horwith $\mathrm{G}$, DeWit S, et al. Pharmacokinetic profile of ABELCET (amphotericin B lipid complex injection): combined experience from phase I and phase II studies. Antimicrob Agents Chemother. 1997;41:2201-8.

112. Fontenele e Silva JS, Galvao TF, Pereira MG, Silva MT. Treatment of American tegumentary leishmaniasis in special populations: a summary of evidence. Rev Soc Bras Med Trop. 2013;46:669-77.

113. Zheng G, Zhong H, Guo Z, Wu Z, Zhang H, Wang C, et al. Levels of heavy metals and trace elements in umbilical cord blood and the risk of adverse pregnancy outcomes: a populationbased study. Biol Trace Elem Res. 2014;160:437-44.

114. Mueller M, Balasegaram M, Koummuki Y, Ritmeijer K, Santana MR, Davidson R. A comparison of liposomal amphotericin B with sodium stibogluconate for the treatment of visceral leishmaniasis in pregnancy in Sudan. J Antimicrob Chemother. 2006;58:811-5.

115. Morgan DJ, Guimaraes LH, Machado PR, D'Oliveira A Jr, Almeida RP, Lago EL, et al. Cutaneous leishmaniasis during pregnancy: exuberant lesions and potential fetal complications. Clin Infect Dis. 2007;45:478-82.

116. Bossolasco S, Gaiera G, Olchini D, Gulletta M, Martello L, Bestetti A, et al. Real-time PCR assay for clinical management of human immunodeficiency virus-infected patients with visceral leishmaniasis. J Clin Microbiol. 2003;41:5080-4.

117. Coelho DR, De-Carvalho RR, Rocha RCC, Saint'Pierre TD, Paumgartten FJR. Effects of in utero and lactational exposure to $\mathrm{SbV}$ on rat neurobehavioral development and fertility. Reprod Toxicol. 2014;50:98-107.

118. Miranda ES, Miekeley N, De-Carvalho RR, Paumgartten FJR. Developmental toxicity of meglumine antimoniate and transplacental transfer of antimony in the rat. Reprod Toxicol. 2006;21:292-300.

119. Paumgartten FJR, Chahoud I. Embryotoxicity of meglumine antimoniate in the rat. Reprod Toxicol. 2001;15:327-31.

120. Harstad TW, Little BB, Bawdon RE, Knoll K, Roe D, Gilstrap LC. Embryofetal effects of pentamidine isethionate administered to pregnant Sprague-Dawley rats. Am J Obstet Gynecol. 1990;163:912-6.

121. Dorlo TPC, Balasegaram M, Lima MA, De Vries PJ, Beijnen JH, Huitema ADR. Translational pharmacokinetic modelling and simulation for the assessment of duration of contraceptive use after treatment with miltefosine. J Antimicrob Chemother. 2012;67:1996-2004.

122. Donald PR, Sellars SL. Streptomycin ototoxicity in the unborn child. S Afr Med J. 1981;60:316-8.

123. Pilmis B, Jullien V, Sobel J, Lecuit M, Lortholary O, Charlier C. Antifungal drugs during pregnancy: an updated review. J Antimicrob Chemother. 2014;70:14-22.

124. Novarini A, Montanari A, Bruschi G, Rossi E, Borghetti A, Migone L. The kinetics of aminosidine in renal patients with different degrees of renal failure. Clin Nephrol. 1975;4:23-4.

125. Hernández E, Oliet A, Gallar P, Llanos M, Guerra L, Vigil A. Amphotericin B for visceral leishmaniasis in hemodialysis. Nephron. 1991;59:666.

126. Muther RS, Bennett WM. Peritoneal clearance of amphotericin B and 5-fluorocytosine. West J Med. 1980;133:157-60.

127. Vogelsinger H, Joannidis M, Kountchev J, Bellmann-Weiler R, Wiedermann CJ, Bellmann R. Pharmacokinetics of liposomal amphotericin B during extracorporeal albumin dialysis. Artif Organs. 2006;30:118-21.

128. Bellmann R, Egger P, Gritsch W, Bellmann-Weiler R, Joannidis $\mathrm{M}$, Kaneider N, et al. Amphotericin B lipid formulations in critically ill patients on continuous veno-venous haemofiltration. J Antimicrob Chemother. 2003;51:671-81.

129. Wu JQ, Shao K, Wang X, Wang RY, Cao YH, Yu YQ, et al. In vitro and in vivo evidence for amphotericin B as a P-glycoprotein substrate on the blood-brain barrier. Antimicrob Agents Chemother. 2014;58:4464-9.

130. Osei-Twum J, Wasan KM. Does P-glycoprotein contribute to amphotericin B epithelial transport in Caco-2 cells? Drug Dev Ind Pharm. 2015;41:1130-6.

131. Ménez C, Legrand P, Rosilio V, Lesieur S, Barratt G. Physicochemical characterization of molecular assemblies of miltefosine and amphotericin B. Mol Pharm. 2006;4:281-8.

132. Kip AE, Rosing H, Hillebrand MJX, Blesson S, Mengesha B, Diro E, et al. Validation and clinical evaluation of a novel method to measure miltefosine in leishmaniasis patients using dried blood spot sample collection. Antimicrob Agents Chemother. 2016;60:2081-9.

133. Ayestarán A, López RM, Montoro JB, Estíbalez A, Pou L, Julià $\mathrm{A}$, et al. Pharmacokinetics of conventional formulation versus fat emulsion formulation of amphotericin B in a group of patients with neutropenia. Antimicrob Agents Chemother. 1996;40:609-12. 
134. Benson J, Nahata MC. Pharmacokinetics of amphotericin B in children. Antimicrob Agents Chemother. 1989;33:1989-93.

135. Kan VL, Bennett JE, Amantea MA, Smolskis MC, McManus E, Grasela DM, et al. Comparative safety, tolerance, and pharmacokinetics of amphotericin B lipid complex and amphotericin B desoxycholate in healthy male volunteers. $J$ Infect Dis. 1991;164:418-21.

136. Nath CE, McLachlan AJ, Shaw PJ, Gunning R, Earl JW. Population pharmacokinetics of amphotericin B in children with malignant diseases. Br J Clin Pharmacol. 2001;52:671-80.

137. Drugs for Neglected Diseases initiative. Pharmacokinetics/ safety of miltefosine allometric dose for the treatment of visceral leishmaniasis in children in Eastern Africa [ClinicalTrials.gov identifier NCT02431143]. US National Institutes of Health,
ClinicalTrials.gov. https://www.clinicaltrials.gov. Accessed 12 Jun 2017.

138. International Centre for Diarrhoeal Disease Research, Bangladesh. Miltefosine for children with PKDL [ClinicalTrials.gov identifier NCT02193022]. US National Institutes of Health, ClinicalTrials.gov. https://www.clinicaltrials.gov. Accessed 12 Jun 2017.

139. Drugs for Neglected Diseases. Efficacy trial of ambisome given alone and ambisome given in combination with miltefosine for the treatment of VL HIV positive Ethiopian patients. [ClinicalTrials.gov identifier NCT02011958]. US National Institutes of Health, ClinicalTrials.gov. https://www.clinicaltrials.gov. Accessed 12 Jun 2017. 